\title{
手性伯胺作为有机催化剂对亚胺的不对称反应研究进展
}

\author{
张永娜*段慧欣汪游清* \\ (河南大学化学化工学院 河南省多酸化学重点实验室 河南省天然药物与免疫工程重点实验室 \\ 河南开封 475004)
}

\begin{abstract}
摘要 在不对称有机催化领域, 手性伯胺化合物是一类特别的有机小分子催化剂. 作为手性仲胺催化剂的补充, 它可 以与羰基化合物形成烯胺或者亚胺盐活性中间体来催化各类不对称反应, 在许多不对称转化中具有高对映选择性. 对 亚胺化合物(包括反应过程中涉及到的亚胺中间体)的碳氮双键官能团的不对称 1,2 加成, 是获得 $\alpha$ 位手性含氮化合物的 有效手段. 近年来手性伯胺催化剂对亚胺的高对映选择性的不对称反应取得了一定的进展, 因此对这一领域进行了综 述和展望.
\end{abstract}

关键词 手性; 伯胺; 亚胺; 不对称催化; 有机催化剂

\section{Research Progress in Asymmetric Reactions of Imines Using Chiral Primary Amines as Organocatalysts}

\author{
Zhang, Yongna* Duan, Hui-Xin Wang, You-Qing* \\ (College of Chemistry and Chemical Engineering, Henan Key Laboratory of Polyoxometalate Chemistry, Provincial Key \\ Laboratory of Natural Medicine and Immuno-Engineering, Henan University, Kaifeng, Henan 475004)
}

\begin{abstract}
Chiral primary amine is a kind of important small organic molecule catalyst in the field of asymmetric organocatalysis. Like secondary amine catalyst, primary amine can react with carbonyl compounds to form reactive intermediate of enamine or iminium to catalyze various asymmetric reactions, achieving excellent enantioselectivities. The catalytic asymmetric 1,2-addition to the electrophilic $\mathrm{C}=\mathrm{N}$ double bond of imines (involving imine intermediates in the reaction process) is the most efficient way to obtain nitrogen-containing compounds bearing $\alpha$-chiral center. In recent years, the highly enantioselective asymmetric reaction of imines by chiral primary amine catalysts has made some progress, so this topic is summarized and prospected.

Keywords chirality; primary amines; imines; asymmetric catalysis; organocatalysts
\end{abstract}

由于能实现手性增值, 通过不对称催化反应是获得 手性化合物的最为高效的一种方法, 其中, 发展高效的 手性催化剂是各种不对称反应获得高活性和高对映选 择性的关键 ${ }^{[1]}$. 在人工设计化学催化剂方面, 继金属催 化之后，不含金属的有机小分子催化剂由于操作简单、 对空气和水不敏感, 并且得到的产物无重金属残留等优 点, 已经迅速发展并成为有机化学中最活跃和最有吸引 力的研究领域之一 ${ }^{[2 \sim 5]}$

手性有机胺广泛分布在自然界中, 手性来源广泛. 用手性有机胺化合物直接作为催化剂, 不仅原料易得,
并且手性骨架结构多样，能有效进行改造和修饰，可以 得到结构丰富的手性催化剂. 因而, 近年来在有机催化 发展中, 对手性有机胺催化剂进行了大量研究, 已经证 实手性有机胺催化剂对大量的不对称反应取得了好的 活性和优秀的立体选择性. 有机胺类化合物按氮上的取 代基不同可以分为叔胺(Tertiary Amine)、仲胺(Secondary Amine)和伯胺(Primary Amine)三类, 因它们具有不同的 化学性质，导致对底物的活化模式各有特点. 普遍情况 下如 Scheme 1 所示, 手性叔胺催化剂一般起有机碱的 作用, 既能作为 Brønsted 碱与质子结合, 又能作为

\footnotetext{
* Corresponding authors. E-mail: zhangyongna@henu.edu.cn; wyouqing@hotmail.com

Received August 22, 2019; revised November 1, 2019; published online February 29, 2020.

Project supported by the National Natural Science Foundation of China (No. U1404211), and the Key Scientific and Technological Research Projects of Henan Education Department (No. 14A150029).

国家自然科学基金(No. U1404211)、河南省教育厅科学技术研究重点(No. 14A150029)资助项目.
} 
Lewis 碱进入空轨道, 活化底物形成具有活性的亲核给 体(Scheme 1a) ${ }^{[6,7]}$; 而手性伯胺和仲胺催化剂能与羰基 化合物作用, 形成具有更低 LUMO 轨道能量的亚胺盐 活性中间体 ${ }^{[8]}$ 或具有更高 HOMO 轨道能量的烯胺中间 体 $^{[9,10]}$ (Scheme 1b).

(a)

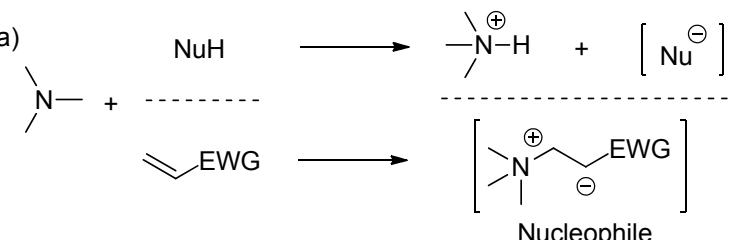

(b)

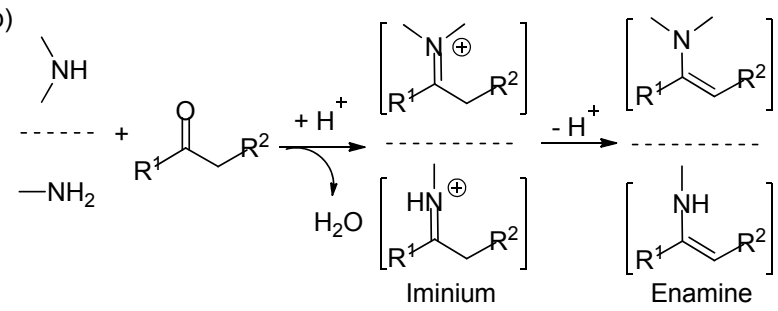

图式 1 胺作为有机催化剂的活化模式

Scheme 1 Activation modes of amine organocatalysts

伯胺催化剂和仲胺催化剂在不对称反应中对底物 的活化模式有很多相似点，一般情况下，如 Scheme 2 所 示, 仲胺和伯胺作为催化剂与羰基化合物形成亚胺离子 中间体或烯胺中间体. 通过亚胺离子活化能降低亲电试 剂的 LUMO 能级, 使其更易受亲核试剂的进攻(Scheme $2 \mathrm{a})^{[8]}$; 而通过烯胺中间体增加了亲核试剂的 HOMO 能 级, 促进其与亲电试剂的反应 (Scheme $2 b)^{[9,10]}$. 约二十 年前, List 等 ${ }^{[11]}$ 将脯氨酸用于催化未修饰的丙酮和各种 醛的直接不对称 Aldol 反应后, 标志着有机催化研究领 域的复兴. 在这阶段前十多年, 以脯氨酸及其衍生物 ${ }^{[2]}$ 和手性联芳基骨架 ${ }^{[13]}$ 为代表的仲胺有机催化剂蓬勃发 展, 实现了催化大量高对映选择性的反应 ${ }^{[8 \sim 10,11,12]}$. 最 近十多年, 手性伯胺催化剂的研究也取得了许多令人振 奋的发现, 在多种类型的不对称催化反应中表现出高效 的催化活性和立体选择性 ${ }^{[14 ~ 19]}$. 其中罗三中 ${ }^{[17,18,20]}$ 和陈 应春 ${ }^{[15,21]}$ 等不仅在手性伯胺催化剂早期发展中参与了 开创性的工作，而且在最近十年来也发展了一些用手性 伯胺催化剂高对映选择性的化学反应. 同样是通过烯胺 和亚胺离子活化, 伯胺和仲胺催化各有特点, 在实现高 对映选择性的反应中互为补充. 相比于仲胺催化剂, 伯 胺催化剂主要特色如下: 一是在形成的亚胺盐或烯胺中 间体结构中，伯胺催化剂氮原子上存在的氢，既可以促 进活性催化中间体的有效形成, 也可能稳定过渡态的立 体构型，从而得到高立体选择性产物; 二是伯胺相对具 有较小的位阻, 可以克服含有较大取代基羰基化合物作 为底物存在的位阻问题, 例如 $\alpha, \beta$-不饱和酮和 $\alpha$ 取代的 $\alpha, \beta$-不饱和醛等 ${ }^{[18]}$. 在自然界中, 天然酶如 I 型醛缩酶和 脱羧酶通常是使用赖氨酸部分的伯胺形成烯胺中间体 进行催化的 ${ }^{[22]}$.

(a) Iminium activation

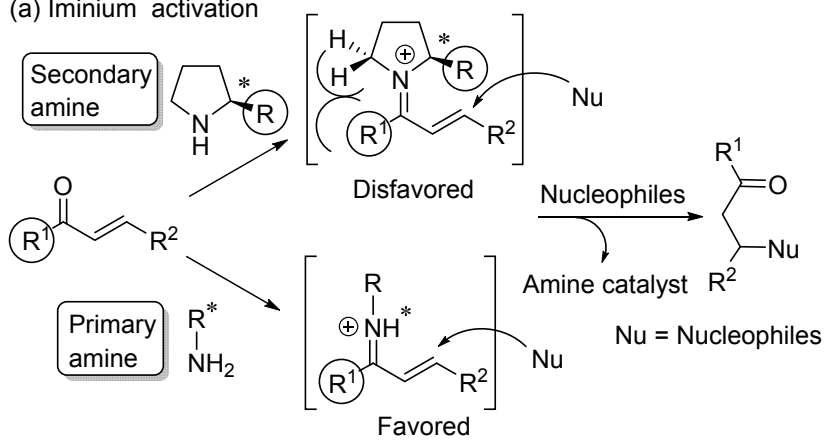

(b) Enamine activation

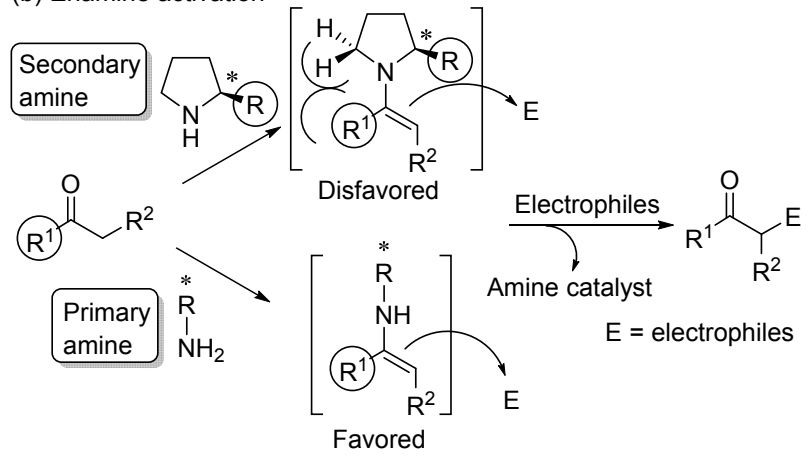

图式 2 伯胺和仲胺在烯胺和亚胺离子的活化过程催化作用 比较

Scheme 2 Catalysis comparison between primary amine and secondary amine in iminium and enamine activation modes

手性含氮化合物广泛分布在天然产物中，其含氮结 构单元对它们的生物活性起着很重要的作用, 并且由于 氮的孤对电子能作为一个碱, 使得它们自己本身就能作 为一个手性配体起到不对称催化作用，它们也是一类重 要的有机中间体和手性助剂. 因此, 实现高效、高选择 性的手性含氮化合物的合成有着重要的意义. 从原子经 济性的角度来说，对于手性含氮化合物的合成最有效的 策略是对含有 $\mathrm{C}=\mathrm{N}$ 潜手性的亚胺不对称加成 ${ }^{[23,24]}$, 也 包括酮亚胺的不对称氢化 ${ }^{[25,26]}$, 这样所得到的产物手性 中心是产生在离氮最近的 $\alpha$ 位, 通过在这类反应中加入 手性催化剂进行手性增值的催化不对称合成方法无疑 是获得这类手性含氮化合物最高效途径(Scheme 3). 然 而, 相比于对含潜手性 $\mathrm{C}=\mathrm{C}$ 键和 $\mathrm{C}=\mathrm{O}$ 键化合物的不 对称反应，伯胺催化含潜手性 $\mathrm{C}=\mathrm{N}$ 键的亚胺化合物的 不对称反应这一具有挑战的领域发展相对缓慢. 在研究 环状亚胺的一些不对称反应时, 我们发现伯胺有机催化 剂能适用于这类反应，从而获得高对映选择性. 因此, 本文对伯胺作为有机催化剂对含有 $\mathrm{C}=\mathrm{N}$ 键的亚胺的不 对称反应进行综述，其中所定义的亚胺的不对称反应特 
指对潜手性 $\mathrm{C}=\mathrm{N}$ 键的对映选择性加成得到含有 $\alpha$ 位手 性中心的含氮化合物结构.

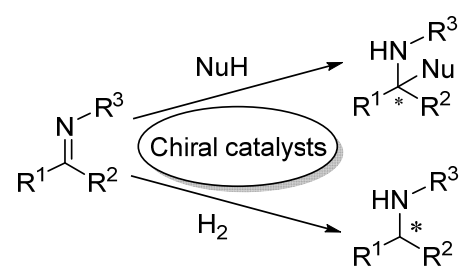

图式 3 亚胺的催化不对称转化

Scheme 3 Catalytic asymmetric transformations of imines.

另外, 本文的亚胺针对一个较广的范围, 不仅为上 面提到的直接用亚胺作为底物, 而且也包括在反应过程 中涉及到对含有潜手性碳氮双键中间体的对映选择性 加成反应. 因此, 对于 $\alpha$ 位含有亚甲基的胺类化合物, 通过氧化或者氢迁移反应能原位产生 $\mathrm{C}=\mathrm{N}$ 键中间体 (亚胺盐), 然后在手性伯胺催化剂存在下, 对碳氮双键 进行对映选择性加成得到产物, 即总反应为胺的 $\alpha$ 位 $\mathrm{C}\left(\mathrm{sp}^{3}\right)$ - $\mathrm{H}$ 催化不对称官能团化(Scheme 4) ${ }^{[27,28]}$, 该类型 反应也在本文综述范围内.

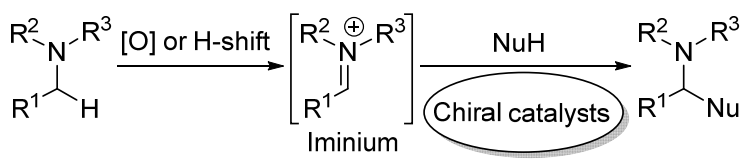

图式 4 胺的 $\alpha$ 位 $\mathrm{C}\left(\mathrm{sp}^{3}\right)-\mathrm{H}$ 催化不对称官能团化 Scheme 4 Catalytic asymmetric $\alpha-\mathrm{C}\left(\mathrm{sp}^{3}\right)-\mathrm{H}$ functionalization of amines

\section{1 用于亚胺不对称反应的手性伯胺催化剂骨架}

用于亚胺的不对称反应的手性伯胺催化剂, 结构如 图 1 所示. 按伯胺官能团所在的手性骨架来源, 可以将 它们分为以下三类: (1)天然 $L$ 型氨基酸及其衍生的手性 伯胺催化剂(Natural $L$-amino acids and their derivatives); (2)金鸡纳生物碱衍生的手性伯胺催化剂(Cinchona alkaloids derivatives); (3)手性 1,2 二胺衍生的伯胺催化剂 (Chiral 1,2-diamines derivatives). 下面将按所用到的这 三类催化剂的类型进行分类, 对其在亚胺中的不对称反 应中的应用进行讨论.

\section{2 对亚胺的催化不对称反应应用}

\section{1 天然 $L$ 型氨基酸及其衍生的手性伯胺催化剂}

氨基酸由于其结构简单、廉价易得、可控位点较多 等优点, 已成为最具价值的有机催化剂来源之一. 直接 利用非环状天然 $L$ 型氨基酸就能作为伯胺催化剂, 并且 氨基酸种类较多且易于修饰, 在对含 $\mathrm{C}=\mathrm{N}$ 键化合物的 不对称反应表现出好的活性和高的立体选择性.
(1) Natural $L$-amino acids and their derivatives

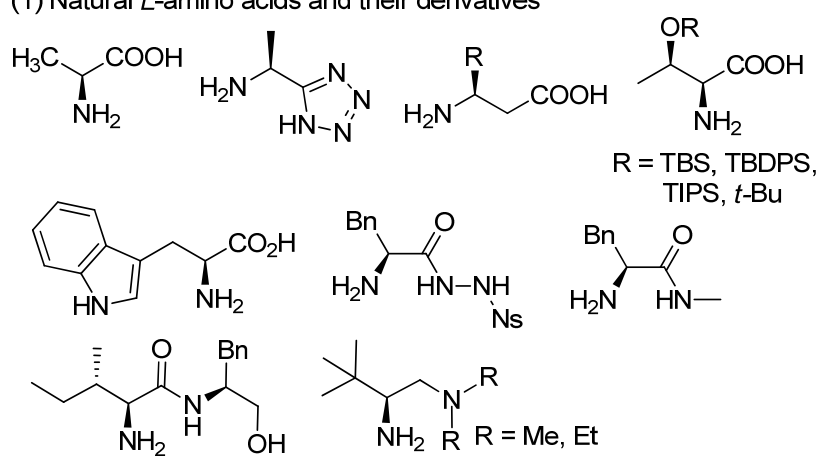

(2) Cinchona alkaloids derivatives<smiles>[X][X]c1ccc([C@H](N)[C@H](N)C2CN3CCC2C(C=C)C3)c2cc([X])ccc12</smiles>

(3) Chiral 1,2-diamines derivatives<smiles>CCOC(=O)[C@H]1CC[C@@H](N)[C@H](N)C1</smiles>

图 1 一些手性伯胺催化剂

Figure 1 Selected chiral primary amine catalysts.

2005 年, Córdova 研究组 ${ }^{[29]}$ 报道了第一个由伯胺氨 基酸催化的不对称 Mannich 反应. 如 Scheme 5 所示，最 优的催化剂为简单的丙氨酸 C-1 和丙氨酸-四唑衍生物 C-2, 对酮 1、醛 2 和对茴香胺 3 的三组分反应，以很高 的化学选择性和立体选择性得到相应的顺式为主的 Mannich 产物 4, 其 $e e$ 可高达 $99 \%$ 以上. 对反应条件的 筛选表明，简单非环状手性天然 $L$ 型氨基酸，如丙氨酸、 丝氨酸、㖪氨酸、苯丙氨酸、天冬氨酸和异亮氨酸等催 化该反应都具有很好的化学选择性，丙氨酸 C-1 和丙氨 酸-四唑衍生物 C-2 给出了最高的不对称诱导. 当供体 为链状或环状酮时, 该反应均表现出很好的非对映选择 性和对映选择性. 作者提出的反应机理为经过伯胺催化 剂与羰基给体形成烯胺中间体完成，原位生成的亚胺与 该手性烯胺中间体反应，得到的亚胺离子产物水解后得 到相应的 Mannich 产物. 通过对产物绝对构型的确认, 推出丙氨酸 C-1 和丙氨酸-四唑衍生物 C-2 催化的不对 称 Mannich 反应分别是通过六元椅式过渡态 I 和 II 进行 的, 其中催化生成的手性烯胺的 $S i$ 面与原位生成的受体 亚胺的 $S i$ 面接触. 

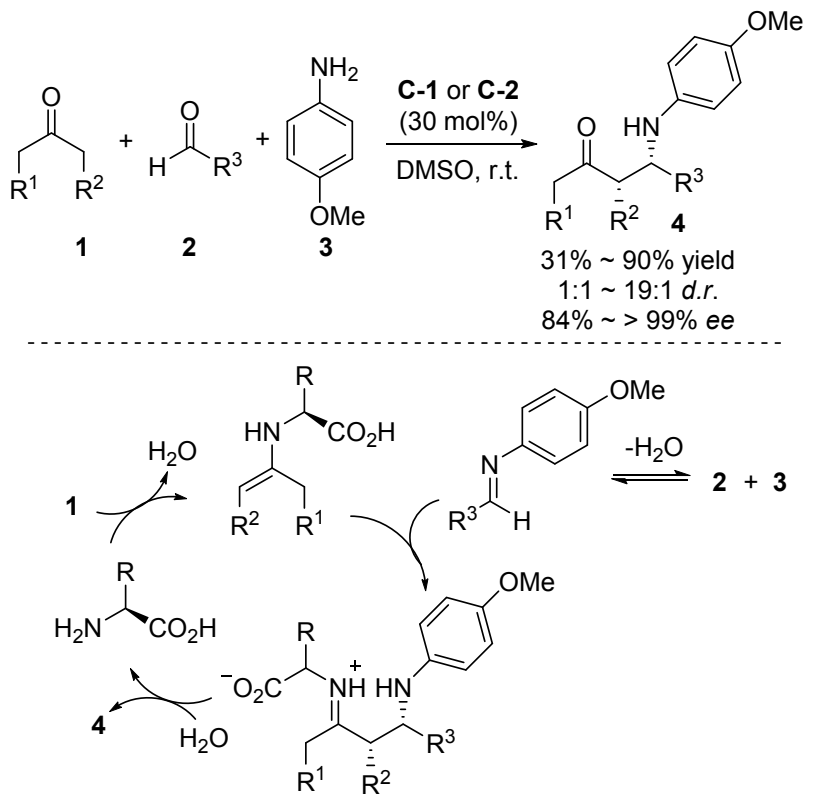

C-1

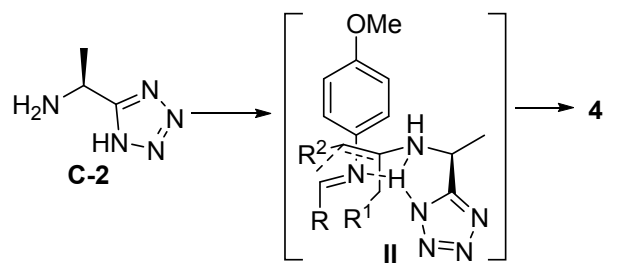

图式 5 伯胺催化的三组分不对称 Mannich 反应

Scheme 5 Amino acid and its derivatives catalyzed asymmetric three-component Mannich reaction

2007 年, Barbas 等 ${ }^{[30]}$ 用手性伯氨基酸作为催化剂实 现了反式 Mannich 反应和顺式 Aldol 反应，如 Scheme 6 所示, 对羟基酮 5 的三组分反式 Mannich 反应能得到具 有光学活性的反式-1,2-氨基醇 6 (Scheme 6). $O$-叔丁基$L$-苏氨酸 $\mathbf{C}-3$ 和 $L$-色氨酸 $\mathbf{C}-4$ 被证明是最好的催化剂,<smiles>[R]CC(=O)CO</smiles>

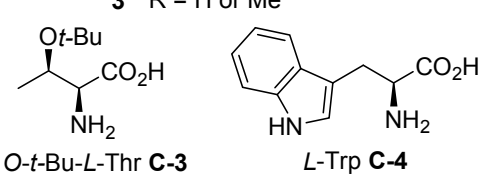

图式 6 有机催化的三组分反式 Mannich 反应合成反式-1,2氨基醇

Scheme 6 Asymmetric synthesis of anti-1,2-amino alcohols through organocatalytic three-component anti-Mannich reactions
用 $N$-甲基吡咯烷酮(NMP)作溶剂时，适合用 $O$-叔丁基$L$-苏氨酸 C-3 作为催化剂, $N, N$-二甲基甲酰胺(DMF)作 为溶剂时，适合用 $L$-色氨酸 C-4 作为催化剂. 在标准反 应条件下, 羟基丙酮 5 还可以与对硝基苯甲醛发生顺 式-Aldol 反应从而得到顺式-1,2-二醇，获得了 $>95 \%$ 的 收率、18/1 顺式 $d r$ 值和 $98 \%$ ee 值.

该项研究工作 ${ }^{[30]}$ 的亮点在于用伯胺催化剂实现了 反式选择性的 Mannich 反应, 而仲胺催化剂得到的是顺 式选择性的 Mannich 反应. 如 Scheme 7 所示, 对仲胺和 伯胺催化的中间体进行比较, 对这种不同选择性进行了 合理分析. 仲胺催化剂 $(S)$-脯氨酸与 $\alpha$-羟基酮形成两种 烯胺中间体，由于空间位阻作用，发生 Mannich 反应时 (E)-烯胺中间体 $\mathbf{A}$ 优于 $(Z)$-烯胺中间体 $\mathbf{B}$, 从而占主导地 位 (Scheme 7a), (E)-烯胺 $\mathbf{A}$ 与亚胺发生 $\mathrm{C}-\mathrm{C}$ 键加成形成 过渡态 $\mathbf{C}$, 最后得到顺式-Mannich 产物. 当伯胺催化剂 与 $\alpha$-着弪基酮形成烯胺中间体时，由于(Z)-烯胺中的羟基 可以和伯胺 $\mathrm{N}$ 原子形成分子内氢键, 所以伯胺催化剂所 形成的 $(Z)$ - 烯胺中间体 $\mathbf{D}$ 优于 $(E)$ - 烯胺中间体 $\mathbf{E}$ (Scheme $7 \mathrm{~b}),(Z)$ - 烯胺 $\mathbf{D}$ 与亚胺发生 $\mathrm{C}-\mathrm{C}$ 键加成形成过渡态 $\mathbf{F}$, 最后反应得到反式-Mannich 产物.
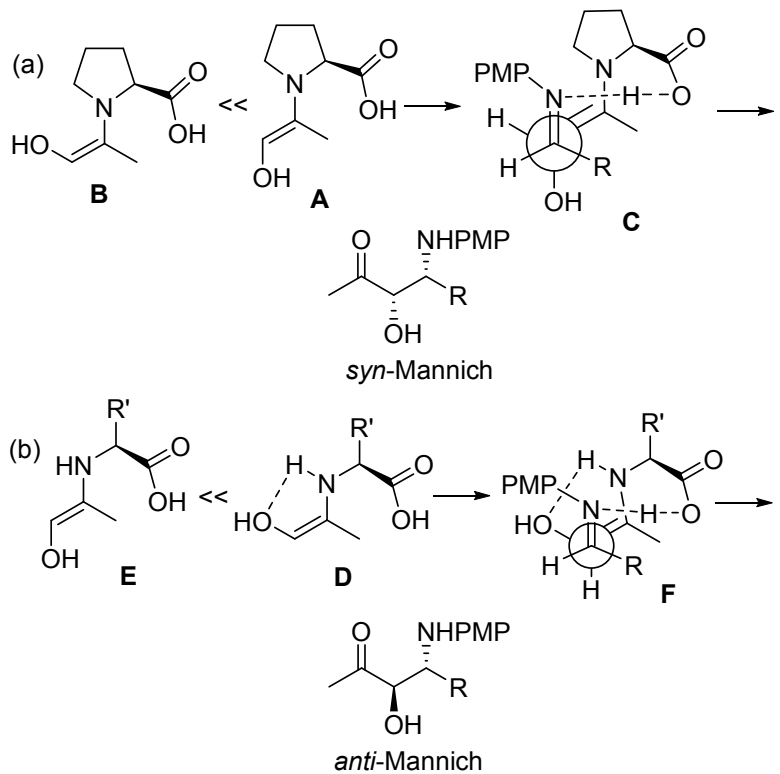

图式 7 仲胺和伯胺催化分别得到顺式和反式 Mannich 产物机 理

Scheme 7 Mechanism of syn- and anti-Mannich products catalyzed by secondary amine and primary amine respectively

紧随其后, $\mathrm{Lu}$ 课题组 ${ }^{[11]}$ 也报道了 $L$-苏氨酸衍生物 C-5 能有效催化对苄基羟基丙酮 7、茴香胺 3 和芳香醛 或脂肪醛在水相中的直接反式 Mannich 反应, 得到具有 高对映选择性(高达 $97 \% \mathrm{ee}$ ) 的反式 1,2-氨基醇 8 (Scheme 8). 该工作首次实现了可以用伯胺氨基酸在水 
溶剂中催化三组分的直接 Mannich 反应, 在没有水的情 况下, 对映选择性较低. 对催化剂的笁选表明苏氨酸衍 生的疏水性有机催化剂比丝氨酸衍生的有机催化剂更 有效. 优化的催化反应条件对各种芳香醛和脂肪醛都能 得到相应的具有很好对映体选择性的 Mannich 产物. 将 氨基醇转化为相应的 Boc 保护的噁唑烷酮, 并与单一构 型的已知化合物进行比较, 确定了产物的相对构型和绝 对构型. 为了解释立体化学结果, 作者提出 Scheme 8 所 示的含多个氢键的过渡态, 由 $O$-茮基羟基丙酮和 $O$-(叔 丁基二苯基硅烷)苏氨酸催化剂生成的烯胺结构的几何 构型为 $Z$, 这可能是由于疏水基团的疏水相互作用或芳 香组分的 $\boldsymbol{\pi}-\boldsymbol{\pi}$ 堆积所致.

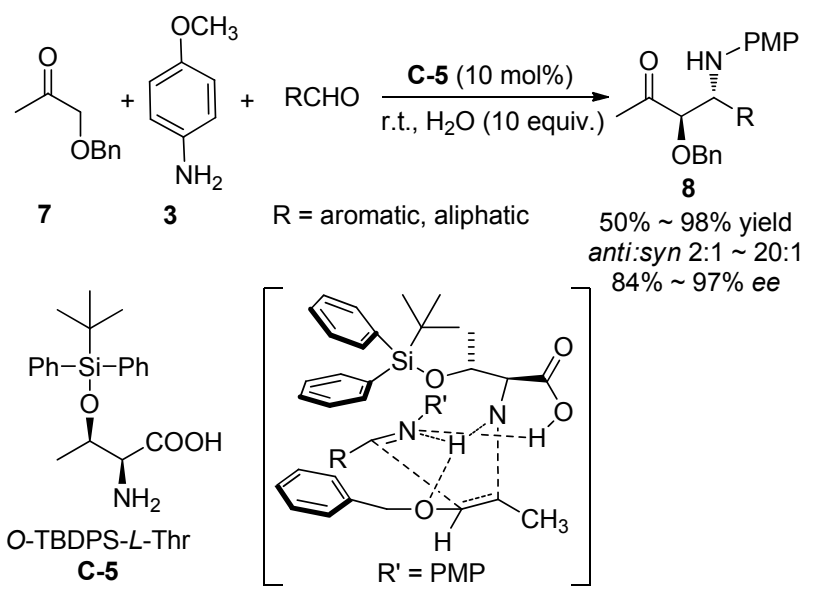

图式 8 在纯水相中的不对称三组分 Mannich 反应

Scheme 8 Asymmetric three-component Mannich reactions in a purely aqueous system

同一年, $\mathrm{Lu}$ 等 ${ }^{[32]}$ 用 $L$-苏氨酸衍生 C-6 作为催化剂, 继续实现了对 $O-\mathrm{TBS}$-差弪基丙酮 9 与芳香醛衍生的 $N$-对 甲苯磺酰亚胺 10 发生反式选择性的 Mannich 反应, 并以 良好的收率和几乎 $99 \%$ 的对映选择性以及最高达

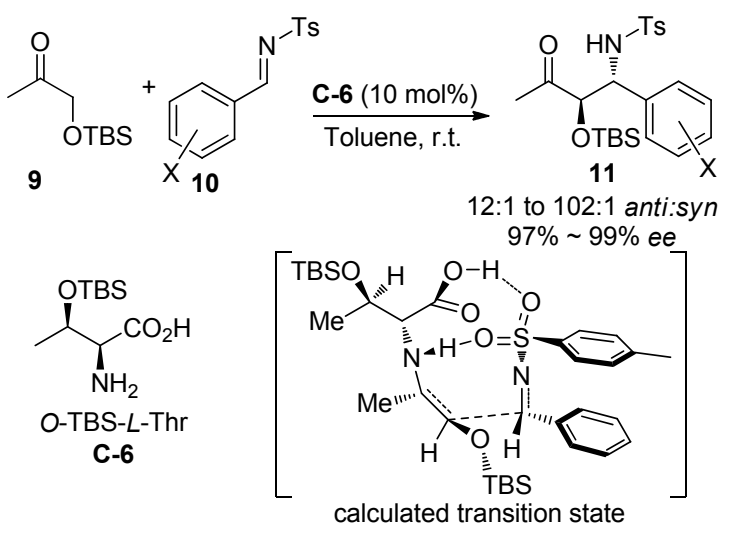

图式 9 苏氨酸衍生物 C-6 催化 $N$-甲苯磺酰亚胺的不对称 Mannich 反应

Scheme 9 Asymmetric Mannich reactions employing $N$-tosylimines catalyzed by $\mathbf{C}-\mathbf{6}$
102：1 的非对映选择性得到了产物 11 (Scheme 9). 不考 虑芳醛的电子性质，该方法几乎适用于任何芳香醛，但 是当使用脂肪醛作为底物时, Mannich 反应不能够进行. 亚胺的氮取代基对于反应的进行至关重要，使用甲磺酰 基取代的亚胺也能得到 $98 \%$ 的 $e e$ 和 $14: 1$ 的 $d r$, 而对 $\mathrm{N}$ 上带有 PMP、Bn 或 Boc 的亚胺只能得到非常差的对映 选择性. 天然色氨酸或苏氨酸对该反应是完全无效的, 说明苏氨酸上羟基位置带有空间位阻的硅氧取代基对 反应顺利进行是关键的. 为了解释反应的立体选择性, 作者也进行了相应的计算研究, 发现砜的两个氧原子分 别与来自 $\mathrm{NH}$ 和羧酸上的活泼氢形成氢键而相互作用.

继上面 Barbas 和 $\mathrm{Lu}$ 发表伯氨基酸催化反式 Mannich 反应论文后同一年, Córdova 课题组 ${ }^{[33]}$ 也报道 了用非环状的 $\beta$-氨基酸催化环己酮和甘氨酸酯衍生的 亚胺 12 的反式选择性 Mannich 反应. 如 Scheme 10 所示, 对不同催化剂研究，非环状 $\beta$-氨基酸 C-7、C-8 和 C-9 催化的反应具有很好的反式选择性，相比之下， $\alpha$-氨基 酸如丙氨酸 C-1 则以较高的顺式选择性催化反应. 有趣 的是，添加少量从 Aldrich 购买的合成海水 ASTM D665 (含 $0.5 \sim 0.9 \mathrm{~mol} / \mathrm{L} \mathrm{NaCl}$ ) 提高了对映选择性, 并加速了 $\beta$-氨基酸催化的反应. 当合成海水被 $0.8 \mathrm{~mol} / \mathrm{L}$ 的 $\mathrm{NaCl}$ 溶液替换时，也能得到相似的结果. 反应扩展到其它环 状酮, 也获得了高的非对映选择性和对映选择性, 以高 达 19：1 的 $d r$ 和 99\% ee 得到相应的手性氨基酸衍生物, 而使用支链酮如 3-戊酩作为供体则反应时间慢，收率低 $(17 \%)$, 但是有较高的对映选择性 $(88 \%)$ )及非对映选择性 $(>19: 1)$.

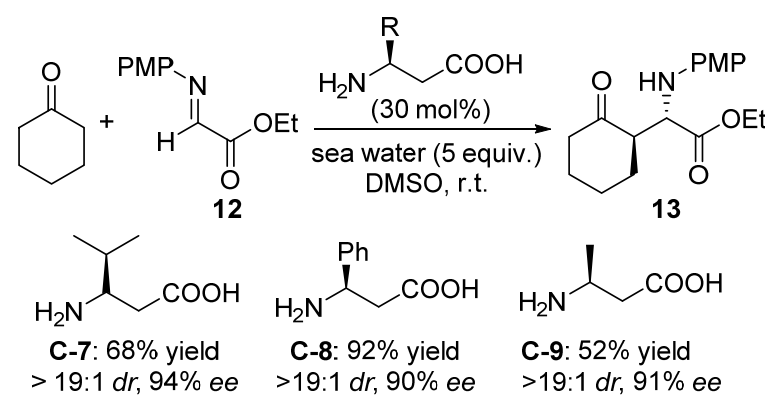

图式 $10 \beta$-氨基酸催化的反式选择性不对称 Mannich 反应 Scheme $10 \beta$-Amino acid-catalyzed asymmetric anti-selective Mannich-type reaction

2008 年, Barbas 等 ${ }^{[34]}$ 继续用 $O$-叔丁基- $L$-苏氨酸 $\mathbf{C - 3}$ 作为催化剂, 实现了二羟基丙酮衍生物 14 和对甲氧基 苯基(PMP)取代的亚胺 15 不对称反式 Mannich 反应，产 物 16 为多着基化合物的氨基糖结构(Scheme 11). 通过 简单的重结晶，所得 Mannich 产物的非对映选择性和对 映选择性可以提高到 99:1 的 $d r$ 和 99\% ee. 并且发现 添加 5-甲基四氮唑，反应的速率和对映选择性均能提 
高. 之前有报道 ${ }^{[35}$ 使用仲胺 $L$-脯氨酸催化二羟基丙酮 衍生物不对称 Mannich 反应，但是只能得到顺式的 Mannich 产物, 并且二羟基丙酮衍生物的底物范围只能 限制为 2,2-二甲 基-1,3-二噁烷-5-酮. 该方法得到的反 式 Mannich 产物能应用于合成各类含胺基的碳水化合 物, 对基于脯氨酸催化策略合成该产物体系是进一步补 充.

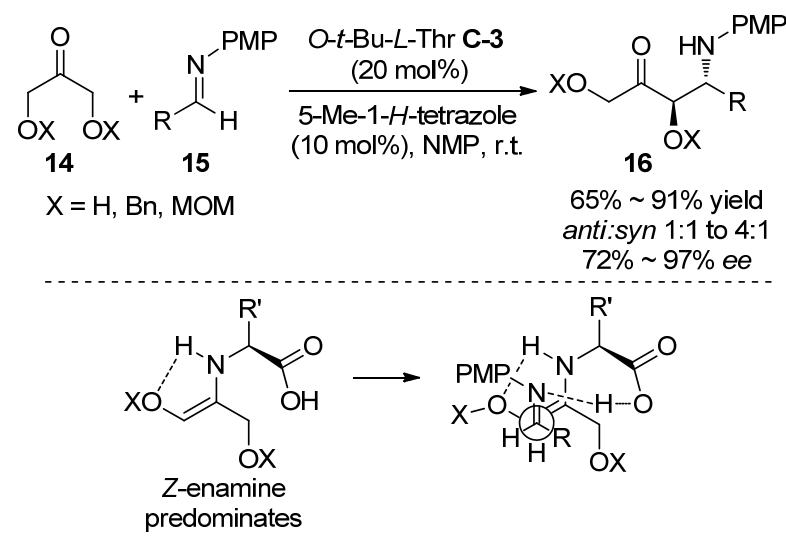

图式 11 手性伯胺催化 Mannich 反应合成氨基糖

Scheme 11 Chiral primary amine catalyzed anti-Mannich reactions to synthesize amino sugars

2013 年王锐等 ${ }^{[36]}$ 通过手性离子对催化策略实现了 无金属催化的不对称氧化脱氢偶联反应, 如 Scheme 12 所示, 在苯丙氨酸 C-10 作为催化剂和 2,3-二氯-5,6-二氰 对苯醌(DDQ)作为氧化剂条件下, 不同取代的四氢异喹 啉 17 和各种酮能发生脱氢偶联反应生成旋光活性的碳 1 位烷基化的四氢异喹啉衍生物 18. 底物扩展实验显示 对环状的酮(环己酮和带杂原子的环状酮)能取得 $3: 1$ $13: 1 d r$ 和 $61 \% \sim 90 \% e e$ 的立体选择性, 对于非环状的 丁酮得到了较差的 $30 \%$ ee 的对映选择性. 作者认为反 应过程包含有单电子转移(SET)阳离子机理过程, 即四 氢异喹啉在 DDQ 存在下发生单电子转移得到自由基阳 离子, 实验推测随后快速的发生不可逆的氢转移过程形

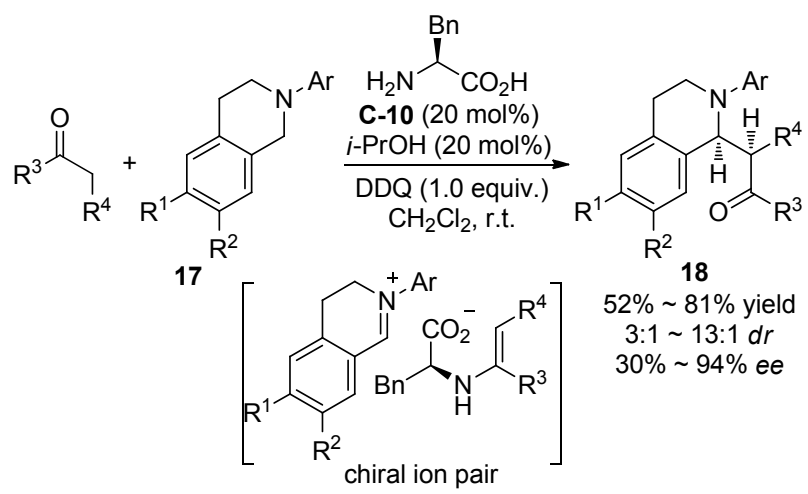

图式 12 对映选择性的叔胺和酮的氧化脱氢偶联

Scheme 12 Enantioselective oxidative cross-dehydrogenative coupling of tertiary amines with ketones
成了含有环内碳氮双键的亚胺盐中间体，该亚胺盐中间 体与催化剂 C-10 和酮形成的烯胺羧基阴离子形成离子 对过渡态，最终通过手性伯胺催化酮对碳氮双键的加成 完成反应.

2014 年 Pan 等 ${ }^{[37]}$ 发现 $L$-苏氨酸衍生物 C-3 或 $L$-叔 亮氨酸 C-11 催化 2-氨基苯乙酮 19 与醛的不对称分子内 的 Mannich 反应，以 $23 \% \sim 75 \%$ 收率和好的对映选择性 获得 2-芳基-2,3-二氢-4-奎诺酮 20 (Scheme 13). 对一些 手性伯胺氨基酸作为催化剂进行了篮选, 发现用 $\mathrm{O}^{t} \mathrm{Bu}-L$-苏氨酸 $\mathbf{C}-\mathbf{3}$ 催化剂在甲醇中能得到最好的对映 选择性, 而用 $L$-叔亮氨酸 C-11 作催化剂在三氟乙醇 (TFE) 能得到最好的对映选择性, 作者最终选用 $\mathrm{O}^{t} \mathrm{Bu}-L-$ 苏氨酸作催化剂进行了底物拓展. 研究结果证实手性伯 胺在该反应的催化效果要优于手性仲胺如脯氨酸. 机理 被认为是伯胺催化剂与酮形成烯胺中间体, 然后从新形 成的碳氮双键的 $S i$ 面进攻，并且催化剂的羧基同时活化 了碳氮双键.
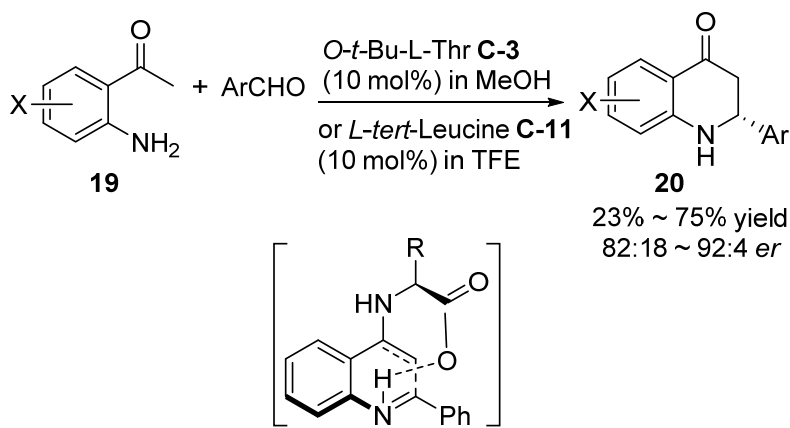

$23 \% \sim 75 \%$ yield $82 \cdot 18 \sim 92 \cdot 4$ er

图式 13 伯胺氨基酸催化的分子内的不对称 Mannich 反应 Scheme 13 Primary amino acid-catalyzed asymmetric intramolecular Mannich reaction

2015 年汪志勇和罗德平等 ${ }^{[38]}$ 报道了 $L$-苯丙氨酸衍 生的含有多个氢键的双官能团手性伯胺磺酰肼 C-12 催 化的五元环状酮亚胺 21 与酮的非对映选择性和对映选 择性 Mannich 反应，有效地构建了四取代的 $\alpha$-氨基酯衍 生物(Scheme 14). 在这一有效的转化过程中, 链状的酮 和环状酮都可以用作底物，分别得到 $\alpha$-氨基酯 22 和 23 . 用活性较低的苯乙䣶代替丙酮作为亲核试剂时, Mannich 产物仍具有好的 $80 \%$ ee 和 $90 \%$ 的收率. 另外, 用乙 醇洗涤产物, 浓缩滤液后得到 $98 \%$ ee 的白色固体, 可进 一步提高产物的对映体选择性. 以 $\alpha$-氨基酯产物 22 为 原料，分三步可以合成具有生物活性的螺四氢呋喃，生 理活性测试显示 $\alpha$-氨基酯产物 23 的其中一个具有潜在 的 HIV-1 抑制剂活性.

随后, 汪志勇等 ${ }^{[39]}$ 用 $L$-苯丙氨酸衍生的 C-13 或 $L-$ 异亮氨酸衍生的 C-14 作为催化剂, 报道了氟烷基取代 的醇胺 24 与酮的不对称脱水 Mannich 反应，直接获得了 一系列具有潜在生物活性的 $\beta$-氨基酮 25 (Scheme 15). 

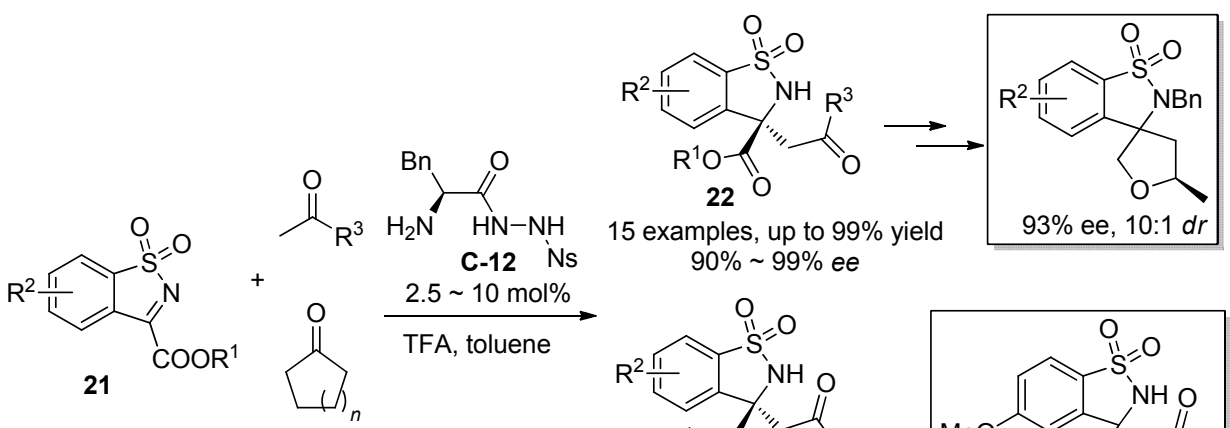

$90 \% \sim 99 \%$ ee

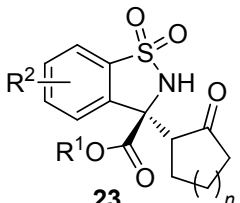

16 examples, up to $99 \%$ yield

$10: 1 \sim>99: 1 d r, 95 \% \sim 99 \%$ e

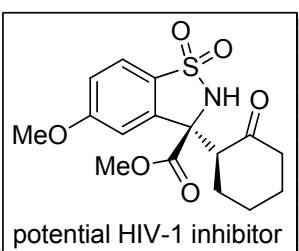

potential HIV-1 inhibitor

图式 14 环状氮磺酰基酮亚胺与酮的直接不对称 Mannich 反应

Scheme 14 Asymmetric Mannich reaction of cyclic sulfonyl ketimines with ketones

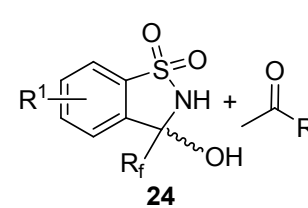

24

$\mathrm{R}_{\mathrm{f}}=\mathrm{CF}_{3}, \mathrm{CF}_{2} \mathrm{H}$ $\mathrm{R}_{\mathrm{f}}=\mathrm{CF}_{2} \mathrm{CF}_{3}$<smiles>CNC(=O)C(N)Br</smiles>
C-13<smiles>[R17]C1=NS(=O)(=O)c2ccccc21</smiles>
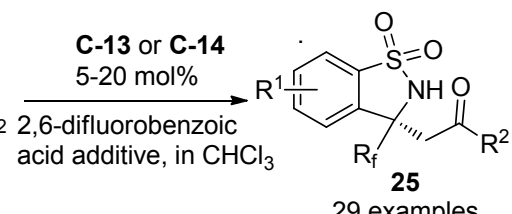

25

29 examples

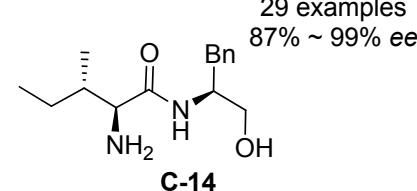

图式 15 氟烷基醇胺与酮的不对称脱水 Mannich 反应

Scheme 15 Asymmetric dehydrated Mannich reaction of fluoroalkylated hemiaminals with ketones

使用两种不同的氨基酸伯胺催化剂对于烷基酮或者芳 基酮的底物都具有非常好的对映选择性(高达 99\%), 在 该 Mannich 反应中, 以前较少探索的芳基酮显示出很好 的反应性. 作者通过 ${ }^{19} \mathrm{~F}$ NMR 检测到了参与脱水 Mannich 反应的两个中间产物 I 和 II, 并通过 HRMS 进 一步确定了中间体的结构. 考虑到反应中存在原位生成 的酮亚胺, 在标准反应条件下, 作者对脱水的酮亚胺底 物进行了尝试, 得到了 $92 \% e e$ 和 $99 \%$ 的收率, 这一发现 证实了该脱水 Mannich 反应经过原位产生的酮亚胺中间 体完成.

硝酮(Nitrone)是亚胺的 $\mathrm{N}$-氧化物, 对用其作为底物 涉及到碳氮双键参与反应产生 $\alpha$ 位立体手性中心含氮化 合物的反应也进行介绍. 硝酮的碳氮双键除了具有亚胺 作为亲电受体的性质外, 其与氮相邻的氧还能作为亲核 给体, 因此能作为 1,3-偶极体发生 1,3-偶极环加成反应. 2015 年, Kwon 和 Nakano ${ }^{[40]}$ 设计合成了一类含有超大体
积硅基伯氨基醇 C-15 作为有机催化剂, 能成功应用于 硝酮 26 和 $\alpha, \beta$ 不饱和醛(巴豆醛和丙烯醛)的 1,3-偶极环 加成反应(Scheme 16). 在对不同硝酮的底物实验中均 得到 endo 构型选择性的五元环异恶唑啉 $\mathbf{2 7}$ 为产物, 并 取得了 $67 \% \sim 97 \% e e$ 高的对映选择性，用巴豆醛作为底 物取得了好的非对映选择性(89：11 96:4 endo/exo), 优于丙烯醛作为底物的非对映选择性 $(61: 39 \mathrm{endo} /$ exo). 得到的异恶唑啉产物能通过还原开环转化为含有 三个手性中心的 $\gamma$ 氨基二醇. 作者推测的反应过程为伯 胺催化剂、三氟甲磺酸和 $\alpha, \beta$ 不饱和醛现成具有更低 LUMO 轨道能量的亚胺盐活性中间体, 然后该中间体 与硝酮发生环加成反应, 过渡态的理论计算显示超大体 积硅基 TTMSS (tris(trimethylsilyl)silyl)作为位阻基团对 反应的选择性起到重要的作用, 进一步理论计算显示中 间体亚胺盐活性中间体的 LUMO 和硝酮的 HOMO 轨道 相互作用是匹配的, 允许环加成反应发生.

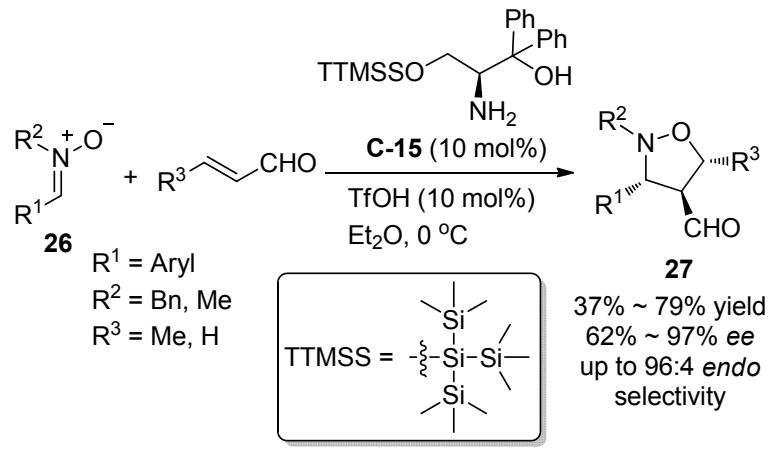

图式 16 硅氧伯氨基醇 C-15 催化硝酮的不对称 1,3-二偶极环 加成

Scheme 16 Silyloxy primary amino alcohol C-15 catalyzed asymmetric 1,3-dipolar cycloaddition of nitrones

2017 年, 邵志会等 ${ }^{[41]}$ 报道了 $L$-叔亮氨酸衍生的手 性伯胺 C-16 催化的醛与酮亚胺 28 和 30 的不对称 
Mannich 反应(Scheme 17). $N$-Boc 靛红酮亚胺 28 和醛在 有机溶剂或水性介质中能发生对映选择性 Mannich 反 应，对于乙醛能得到 90\% 94\% ee 值, 对其它醛得到高 非对映选择性和对映选择性的反式 Mannich 产物 29 $(90 \% \sim 97 \% e e)$. 值得注意的是, 当使用脯氨酸衍生的 仲胺催化该反应, 则得到与之相反的顺式Mannich 产物, 也具有优异的对映选择性( $92 \%$ \% $\%$ ee). 该伯胺催化 体系对环状的三氟甲基取代的酮亚胺 30 和乙醛也能实 现高对映选择性的 Mannich 反应，以 $90 \%$ ～95\% ee 值获 得产物 31, 而使用手性仲胺作催化剂则不能催化该反 应的进行. 随后, Houk 等 ${ }^{[42]}$ 通过密度泛函理论(density functional theory)计算和扭曲相互作用(distortion-interaction)分析, 从理论上证明了该 Mannich 反应的手性产 生过程. 计算结果表明, 优势过渡态虽然为含有氢键的 九元环状结构, 但是在能量上非常稳定, 该优势过渡态 为含有八个重原子的冠状(椅式一椅式)构象, 亚胺底物 的氮上 Boc 基团和伯胺催化剂 C-16 的叔丁基之间相互 引起位阻作用.<smiles>CN1C(=O)/C(=N\C(=O)O)c2c[R1]ccc21</smiles>

$28 \stackrel{1}{R}{ }^{2}$

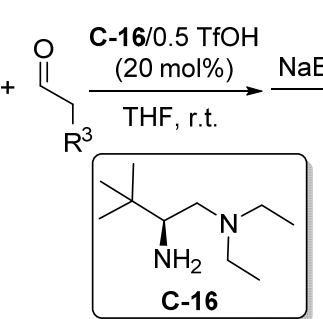
C-16

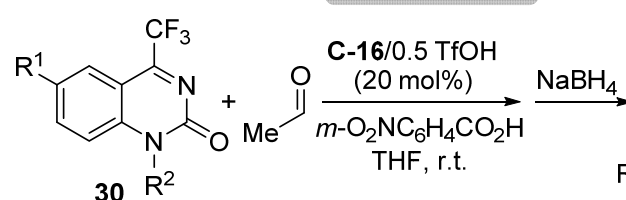
$30 R^{2}$ THF, r.t.$$
75 \% \sim 90 \% \text { yield }
$$

图式 17 手性伯胺 C-16 催化酮亚胺的不对称 Mannich 反应 Scheme 17 Chiral primary amine C-16 catalyzed asymmetric Mannich reactions of ketimines

2017 年罗三中等 ${ }^{[43]}$ 开发了亚胺前体试剂 $N, O$-乙缩 醛 32 的不对称 Mannich 反应, 在手性伯胺 C-17 催化作 用下, 以近乎光学纯的立体选择性地高效合成了一系列 $\beta$-氨基羰基以及 $\alpha$-氨基酸酯化合物 33 (Scheme 18). 甲 醛的不对称 Mannich 反应(也称为氨甲基化反应)以及乙 醛酸酯的不对称 Mannich 反应是合成手性 $\beta$-氨基酸以及 $\alpha$-氨基酸类化合物的有效手段, 但是由于其不稳定容易 自身聚合, 实现其不对称 Mannich 反应具有一定挑战. 在该研究中, 设计了用甲醛与乙醛酸酯衍生的稳定亚胺 前体试剂 32, 并将其成功应用于链状和环状的 $\beta$ 酮羰基 化合物 $\alpha$ 位的不对称 Mannich 反应, 高效、立体专一地
合成了手性的 $\alpha$-和 $\beta$-氨基的羰基类化合物 33，该反应 对其它非官能团酮底物，如丙酮、环戊酮和环己酮，也 能获得高的对映选择性(94\% 98\% ee). 基于实验结果 以及该课题组以往的研究, 提出了如下的反应过渡态: 首先, 亚胺前体试剂 32 在伯胺催化剂的作用下原位产 生亚胺中间体, 烯胺从 $R e$ 面与亚胺发生加成, 质子化叔 胺的 $\mathrm{N}-\mathrm{H}$ 键与亚胺(I)或亚胺酯(II)之间的氢键作用决 定了反应具有很高的对映选择性以及非对映选择性. 随 后，该研究团队 ${ }^{[44]}$ 将同样的 Mannich 反应继续拓展到了 含氟或含氯基团取代的 $N, O$-乙缩醛, 即 Scheme 18 中 $N, O$-乙缩醛 32 的 $\mathrm{R}$ 为 $\mathrm{CF}_{3}, \mathrm{CF}_{2} \mathrm{H}, \mathrm{C}_{2} \mathrm{~F}_{5}$ 和 $\mathrm{CCl}_{3}$ 等基团, 用同样的手性伯胺 C-17 和三氟甲基磺酸盐作为催化剂. 主要进行了两类底物的拓展实验, 对含 $\mathrm{CF}_{3}$ 的 $N, O$-乙缩 醛进行底物实验时 $\mathrm{N}$ 上保护基为 $\mathrm{Cbz}$ 时立体选择性最 佳，取得了 $98 \%$ ～> 99\% ee 优秀对映选择性，不同酮底 物导致了差别比较大的非对映选择性; 对含 $\mathrm{CF}_{2} \mathrm{H}$ 的 $\mathrm{N}, \mathrm{O}$-乙缩醛进行底物实验时 $\mathrm{N}$ 上保护基为 Fmoc 时立体 选择性最佳, 取得了 $95 \%$ > $99 \%$ ee 优秀对映选择性.

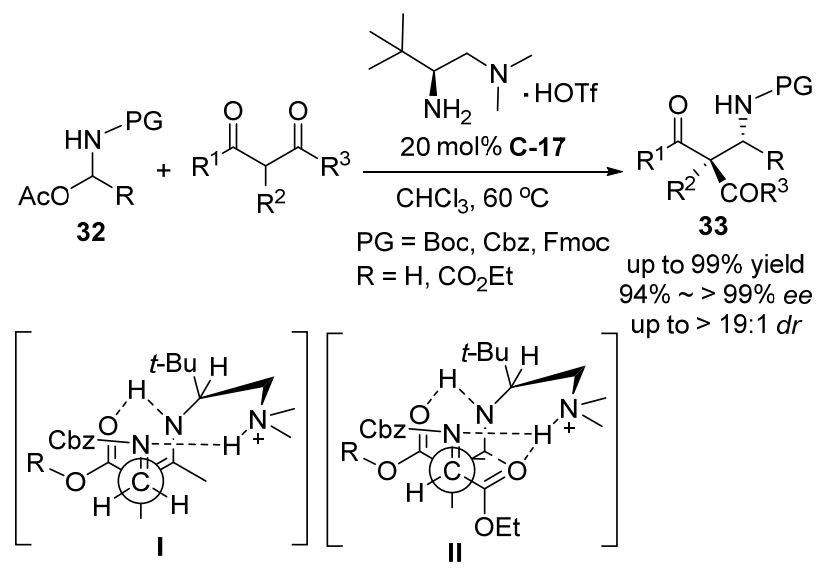

图式 $18 \mathrm{~N}, \mathrm{O}$-缩醛被用作为 $\mathrm{N}$-氨甲酰基亚胺等价体的催化不 对称 Mannich 反应

Scheme 18 Catalytic asymmetric Mannich reaction using $N, O$ acetals as $\mathrm{N}$-carbamoyl imine surrogates

2018 年, Rueping 等 ${ }^{[45]}$ 用可见光氧化还原催化剂和 手性伯胺有机催化剂合并的催化体系, 实现了四氢异喹 啉 17 和环状酮的氧化交叉脱氢偶联的不对称 $\alpha$-烷基化 反应(Scheme 19). 在这一双催化体系中, 四氢异喹啉 $\mathbf{1 7}$ 被可见光氧化还原催化剂活化, 酮被手性伯胺催化剂活 化，在对一系列伯氨基酸作为手性伯胺催化剂进行笁选 中, 发现最优的手性伯胺催化剂为苯甘氨酸 C-18. 并且 该反应的加料顺序能明显提高对映选择性，通过对可见 光催化剂和手性伯胺催化剂进行分段试验操作的方式, 在优化条件下，能以好的收率、高的对映和非对映选择 性得到目标产物 $\mathbf{3 4}$. 


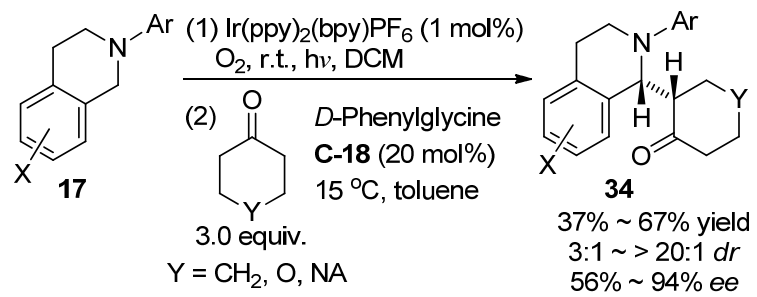

图式 19 四氢异喹啉和环状酮的不对称 $\alpha$-烷基化 Scheme 19 Asymmetric $\alpha$-alkylation of tetrahydroisoquinolines with cyclic ketones

2019 年, 罗三中等 ${ }^{[46]}$ 用其研究团队开发的手性伯 胺 C-16 和三氟甲磺酸成盐作为伯胺有机催化剂, 也能 实现硝酮 26 和环状烯酮 35 的不对称 1,3-二偶极环加成 反应，以好到优秀的对映和非对映选择性得到含有多个 立体中心的稠合双环异恶唑啉结构化合物 36 (Scheme 20). 作者也给出了该反应的机理过程, 伯胺催化剂与 烯酮形成具有更低 LUMO 轨道能量的亚胺盐中间体作 为亲偶极体，随后通过如 Scheme 20 所示的过渡态发生 环加成反应, 硝酮可以认为既作为氧亲核给体又作为含 有碳氮双键的亲电受体.

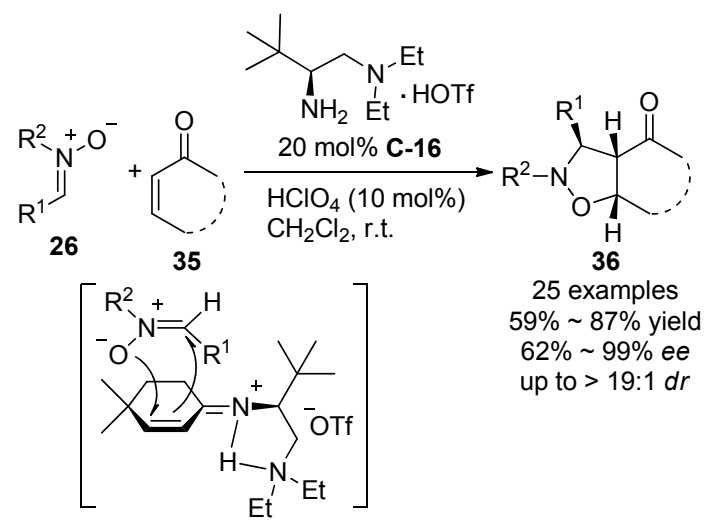

图式 20 伯胺催化作用的硝酮和烯酮的不对称 1,3-二偶极环 加成

Scheme 20 Asymmetric 1,3-dipolar cycloadditions between nitrones and enones by primary amine catalysis

\section{2 金鸡纳生物碱衍生的手性伯胺催化剂}

金鸡纳碱是存在于金鸡纳类植物树皮中的一类天 然产物, 目前分离出来的最受关注的是奎宁、奎尼丁、 辛可宁、辛可尼丁四种. 金鸡纳生物碱及其衍生物一直 以来都以医学药用为主, 近 30 年来人们才将其用作手 性试剂、手性配体以及优先考虑的手性催化剂用于不对 称合成中. 其中, 用于不对称反应的伯胺催化作用的金 鸡纳生物碱催化剂均为 9-位含有伯胺官能团的金鸡纳 生物碱衍生物 ${ }^{[15,16,47]}$.

2007 年, 四川大学的陈应春等 ${ }^{\left[{ }^{[}\right]}$用金鸡纳生物碱 衍生的具有多重官能团的伯胺催化剂 C-19, 实现了对
映选择性的偶氮次甲基亚胺 37 和环已烯酮 35a 的 1,3二偶极 [3+2]环加成, 以优秀的立体选择性 $(d r>99: 1$, $86 \% \sim 95 \% e e$ ) 构建了一类新颖的三环产物 38 (Scheme 21). 反应条件优化显示了不同的酸对反应活性和对映 选择性影响很大，最后篮选最优的酸为 2,4,6-三异丙基 苯磺酸(TIPBA), 分子篮的加入虽然提高了反应的对映 选择性, 但降低了反应活性. 在催化模型中, 催化剂喹 啉环上的酚羟基与 1,3-二偶极体形成的氢键, 对反应所 得的高立体选择性起到了必要的控制作用.
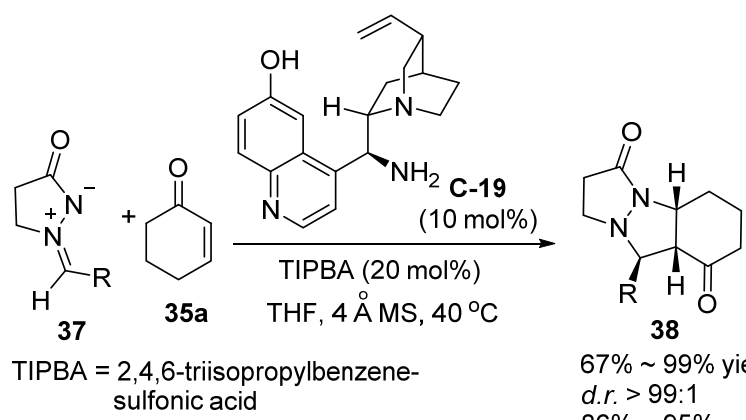

$67 \% \sim 99 \%$ yields d.r. $>99: 1$ $86 \% \sim 95 \%$ ee

图式 21 偶氮次甲基亚胺的对映选择性的 1,3-二偶极 [3+2] 环加成

Scheme 21 Enantioselective 1,3-dipolar [3+2] cycloaddition of azomethine imines

在 2010 年, Zhao 课题组 ${ }^{[49]}$ 和 Xu 课题组 ${ }^{[50]}$ 先后独立 报道了奎宁衍生的伯胺 C-20 作为催化剂, 实现了同样 类型的不对称 Biginelli 反应, 金鸡纳生物碱衍生的伯胺 催化剂也能实现对映选择性的 Biginelli 反应, Biginelli 反应虽然没有直接用到亚胺作为底物进行反应，但是在 该反应过程中，尿素与醛原位产生 $N$-酰基亚胺中间体， 随后其碳氮双键接受伯胺与乙酰乙酸乙酯生成的手性 烯胺中间体作为碳亲核试剂的进攻, 从而产生新的手性 中心, 最后得到手性的二氢吡啶二酮衍生物 39 作为产 物(Scheme 22). Zhao 等 ${ }^{[49]}$ 用伯胺 C-20 和氯化氢作为酸 共催化可以获得最高 $78 \%$ 的 $e e$ 值. 紧随其后, $\mathrm{Xu}$ 等 ${ }^{[50]}$ 发现金属 Lewis 酸作为共催化剂能得到更好的反应活性 和更高的对映选择性，相比更低负载量伯胺催化剂情况 下, 获得更好的收率和最高 $84 \%$ ee 值. Xu 课题组进一 步试验发现，对于模型底物得到的产物(65\%ee), 通过 简单的一次乙醇重结晶，即可获得优秀的 $>99 \%$ ee 值. 随后 2012 年, 周伟等 ${ }^{[51]}$ 也用同样的手性伯胺与金属盐 的复合催化体系, 研究了这个 Biginelli 反应, 对大量的 手性伯胺催化剂和金属盐进行篮选, 篮选的伯胺催化剂 除了有金鸡纳生物碱衍生的伯胺, 还有手性 1,2 二胺衍 生的伯胺以及手性 1,2 二胺和手性氨基酸组合起来的伯 胺, 最后仍然是用奎宁衍生的伯胺 $\mathbf{C - 2 0}$ 和 $\mathrm{NbC1}_{5}$ 共催 化取得最好的结果(74\%收率和 $69 \% e e$ ). 


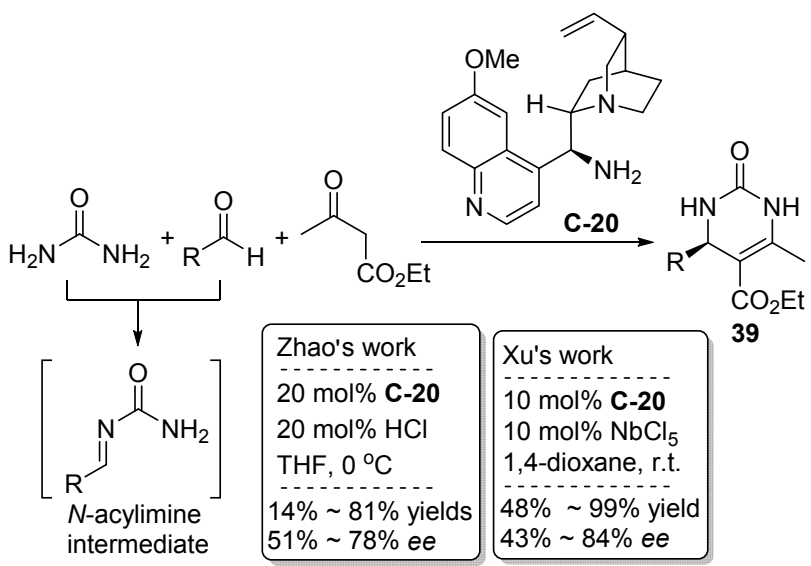

图式 22 奎宁衍生的伯胺催化经过 $N$-酰基亚胺中间体的 Biginelli 反应

Scheme 22 Quinine-derived primary amine catalyzed Biginelli reaction involving $N$-acylimine intermediate

2013 年, 康泰然、刘全忠和何龙等 ${ }^{[52]}$ 用奎尼丁衍生 的伯胺 C-21 和 2-氟苯甲酸合并作为催化剂, 实现了烯 酮 41 或者炔酮 42 对氮磺酰基环状亚胺 40 的 $[4+2]$ 环加 成反应合成了 2,6-二取代的哌啶-4-酮 43 或 44, 对烯酮 底物 41 取得了优秀的 $90 \% \sim 97 \% e e$ 值, 而对炔酮底物 32 取得了略微降低的 $87 \% \sim 91 \%$ ee 值(Scheme 23). 作 者提到, 对于烯酮 41 和氮磺酰基环状亚胺 40 的反应, 有少量的 Mannich 反应产物被观察到. 对于该环加成反 应, 烯酮 41 或者炔酮 42 与伯胺催化剂形成烯胺活性中 间体，接下来烯胺与亚胺底物完成反应存在两种可能, 尽管作者倾向于经过分步的 Mannich-Michael 加成反应 机理，但是也不能排除另一种的协同反应机理.

2013 年, Kim 等 ${ }^{[33]}$ 报道了用奎宁衍生的伯胺 $\mathbf{C - 2 0}$ 实现了四氢异喹啉 45 分子内的不对称 $\mathrm{C}-\mathrm{H}$ 官能团化 (Scheme 24). 该反应的亚胺盐形成过程和氧化脱氢偶 联反应不同, 手性伯胺催化剂与底物作用后, 经过 1,5氢迁移得到了烯胺一亚胺盐的中间体, 该中间体的环化 包含了伯胺催化活化的分子内烯胺对亚胺盐的碳氮双 键的对映选择性的加成过程. 底物实验显示, 该催化体 系对各种含有环状胺和非环状不饱和羰基官能团的底 物都能顺利反应, 以 $51 \% \sim 97 \% e e$ 的对映选择性得到四 氢喹啉衍生物 46 , 但是对于含有环状胺和环己酮官能 团的底物只得到 7\% ee, 对含有非环状胺和非环状不饱 和羰基官能团的底物不能得到目标产物, 这说明该催化 反应体系只对邻位环状含氮官能团取代的芳基不饱和 酮具有活性.

2014 年, 我们课题组 ${ }^{[54]}$ 报道了由奎宁衍生的伯胺 C-20 和 TFA 共催化的甲基烷基酮与环状亚胺苯并 [e][1,2,3]恶噻嗪 2,2-二氧化物 $\mathbf{4 0}$ 的高对映选择性直接 Mannich 反应(Scheme 25). 这是首次实现 $N$-磺酰基环状

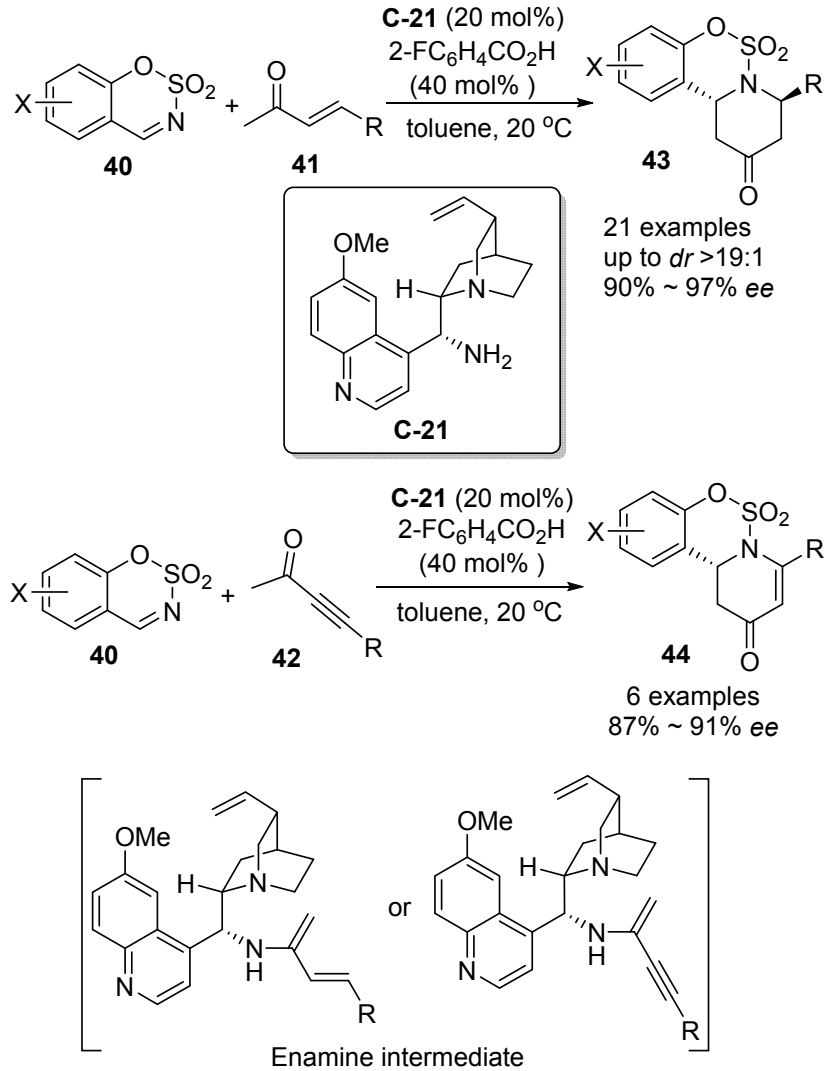

图式 23 奎尼丁衍生的伯胺催化氮磺酰基环状亚胺的对映选 择性[4+2]环加成

Scheme 23 Quinidine-derived primary amine catalyzed enantioselective [4+2] cycloaddition of $N$-sulfonyl cyclic imines

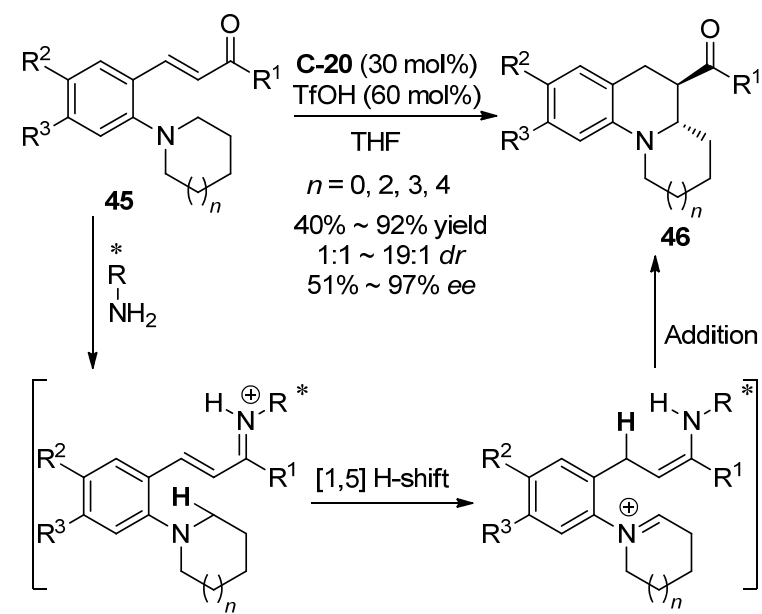

图式 24 通过 1,5-氢迁移的手性伯胺催化的 C-H 官能化 Scheme 24 Chiral primary amine-catalyzed C-H functionalization via 1,5 -hydride transfer

亚胺作为受体的不对称 Mannich 反应, 用常见的仲胺催 化剂脯氨酸的标准条件对该反应没有活性. 对各种取代 的环状亚胺 40 的底物实验, 都能取得高的对映选择性 (93\% 97\% ee). 在用不同的非对称的烷基甲基酮进行 底物实验中, 该催化体系对酮作为给体表现出了高的区 
域选择性, 即完全专一选择在酮的 $\alpha$ 位位阻较小的甲基 位置加成, 然而, 对于甲基叔丁基甲酮底物没有反应活 性，可能因为叔丁基较大位阻的原因. 用 $\mathrm{X}$ 射线单晶衍 射确定了产物的绝对构型, 推测了由丙酮和伯胺催化剂 形成的烯胺中间体的碳亲核基团从 $S i$ 面进攻 $N$-磺酰基 环状亚胺的碳氮双键.

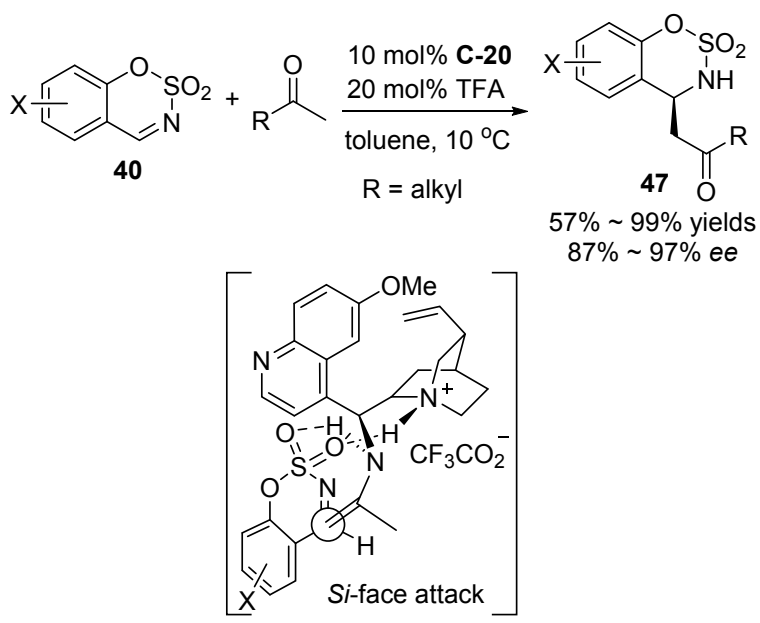

图式 25 甲基烷基酮与氮磺酰基环状亚胺的不对称 Mannich 反应

Scheme 25 Asymmetric Mannich reaction of methyl alkyl ketones with $N$-sulfonyl cyclic imines

随后, 我们课题组 ${ }^{[55]}$ 用相似的伯胺催化体系实现 了低反应活性的芳基酮的不对称 Mannich 反应. 如 Scheme 26 所示, 在伯胺 C-20 和 TFA 共催化条件下能高 对映选择性地构建一系列含有氮氧硫的杂环氨基磺酸 酯类化合物 48. 反应对含不同取代基的亚胺底物 40 和 各种芳基甲基酮都能给出高的对映选择性(89\% 98\% $e e$ ), 苯环上带有给电子基的取代芳基甲基酮在较短的 反应时间内比带吸电子取代基的取代芳基甲基酮具有 更高的产率，由于空间位阻作用，邻位取代芳基甲基酮 的产率和对映体选择性均低于对位取代或间位取代的 芳基甲基酮. 进一步, 含有氮和硫的杂环芳基甲基酮也 能用于该反应, 得到高的对映选择性. 在该研究中, 用 伯胺催化剂能实现活性较低的芳基酮的不对称 Mannich 反应，伯胺催化剂与酮形成烯胺中间体，相比仲胺催化 剂, 其较小的位阻对具有 $\alpha$ 芳基的底物显示出相应的优 势.

\section{3 手性 1,2 二胺衍生的伯胺催化剂}

光学纯的手性 1,2-二胺如环己二胺、二苯二胺, 这 类化合物作为手性源，其原料廉价易得，对其中一个氨 基能方便地衍生为叔胺或其它含有氢键给体官能团, 能 得到含有伯胺的双官能类催化剂, 近来对亚胺的不对称 反应有少量成功的例子报道.
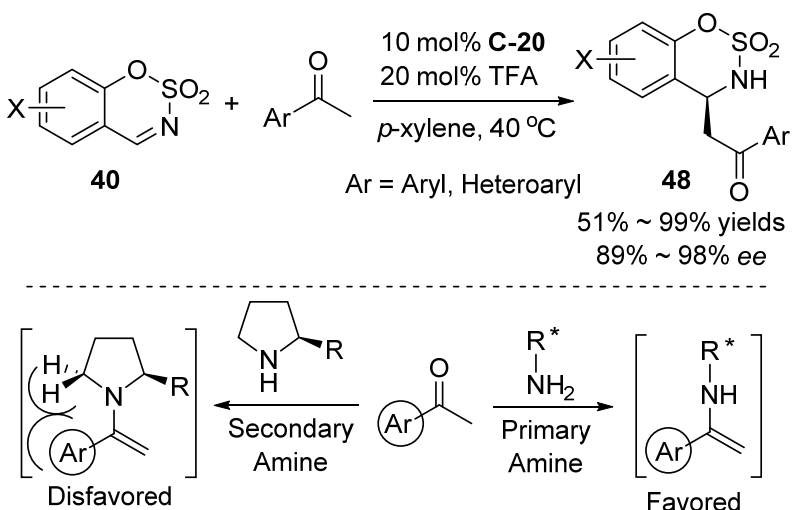

Favored

图式 26 芳基甲基酮与氮磺酰基环状亚胺的不对称 Mannich 反应

Scheme 26 Asymmetric Mannich reaction of aryl methyl ketones with $N$-sulfonyl cyclic imines

2008 年, Tsogoeva 研究小组 ${ }^{[56]}$ 首次将手性伯胺-硫 嫝有机催化剂成功应用于未修饰酮的形式上的不对称 Mannich 反应. 如 Scheme 27 所示, 用手性环己二胺衍 生的伯胺-硫脲 $\mathbf{C}-22$ 作为催化剂, 对含有亚胺基甘氨酸 乙酯 49 和各种链状与环状酮能顺利的反应，以 $45 \%$ $89 \%$ 产率和 $82 \% \sim 99 \%$ ee 得到产物 50, 但是非对映选择 性不是太理想，非环状的酮得到反式产物，而环状酮则 得到过量的顺式产物. 底物扩展实验显示含有支链或具 有空间位阻的酮，其 $e e$ 值高达 $99 \%$ 以上，当底物 49 的 $\mathrm{R}$ 为苯甲酰基时, 苯环上的吸电子取代基提高了反应的速 率，而给电子取代基则降低了反应速率. 不同于常规伯 胺活化羰基化合物烯胺的机理，该反应机理通过计算和 实验证明以烯醇式的机理进行。这是第一个伯胺一硫脲 催化的 $\mathrm{C}-\mathrm{C}$ 键形成 Mannich 型反应的烯醇机理的证据, 进一步发现, 酮的烯醇式与催化剂的结合优先于烯胺的 形成，胺一硫脲可以通过氢键稳定酮的烯醇互变异构.
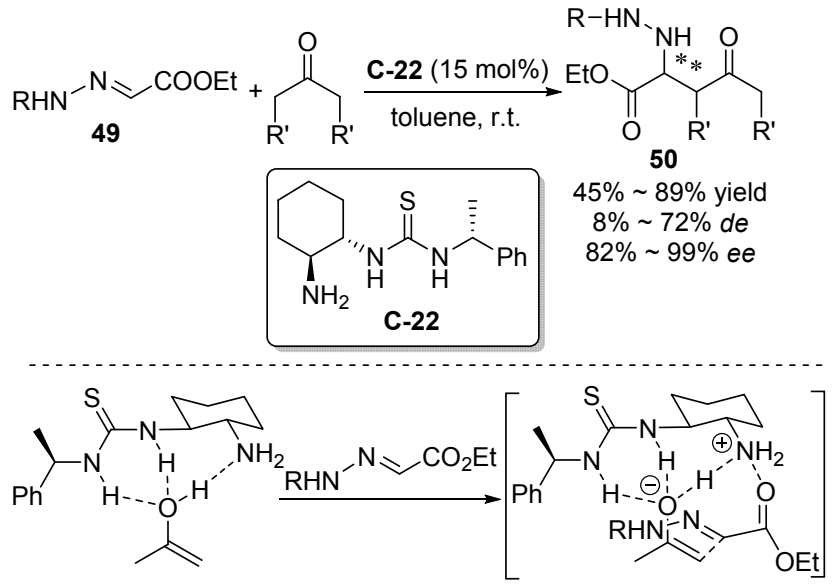

图式 27 伯胺硫脲催化通过烯醇式机理的对映选择性的反应 Scheme 27 Enol mechanism in enantioselective reaction catalyzed by primary amine-thiourea 
2009 年, 苗志伟和陈茹玉等 ${ }^{[57]}$ 用含有手性糖和手 性 1,2-环已二胺结构单元的双官能团伯胺-硫脲催化剂 C-23, 实现了高对映选择性的 Biginelli 反应, 合成了二 氢嘧啶类产物 39 和 51 (Scheme 28). 底物实验发现, 该 催化体系对芳基酫表现出好到高的对映选择性, 但是对 脂肪族醛虽然也能得到目标产物, 但是只获得了很低的 对映选择性. 三氟乙酸的叔丁基胺盐加入能将 $e e$ 值从 $63 \%$ 提高到 $94 \%$ ，显著提高了反应的对映选择性. 三元 化合物的 Biginelli 反应虽然没有直接用亚胺作为底物, 但是在反应过程中经过醛和尿素或者硫䐂原位产生的 $N$-酰基亚胺中间体, 在这里伯胺催化剂与乙酰乙酸乙酯 产生的烯胺中间体对 $N$-酰基亚胺中间体的 $\mathrm{C}=\mathrm{N}$ 立体选 择性加成, 作为关键步骤产生新的手性中心. 随后 2011 年, 他们研究团队 ${ }^{[58]}$ 用同样的伯胺催化剂 C-23 在食盐 水中也实现了 Biginelli 反应, 不同的是用三氟甲磺酸替 代了 2,4,6-三氯苯甲酸, 在研究不同浓度食盐水对反应 影响时, 发现随着食盐浓度增加反应对映选择性增加, 最后在饱和食盐水中对各类不同酫底物获得了 $44 \%$ $>99 \%$ ee 值. 随后 2013 年, 王立新等 ${ }^{[59]}$ 以基于手性 1,2二苯基乙二胺骨架的伯胺-硫艮为催化剂( $20 \mathrm{~mol} \%$ ), 加 入樟脑磺酸 $(20 \mathrm{~mol} \%)$, 实现了靛红、脲和乙酰乙酸乙酯 的一个不对称 Biginelli 反应的例子, 虽然获得了 $79 \%$ 的 收率, 但是对映选择性非常低, 仅为 $22 \% e e$ 值.
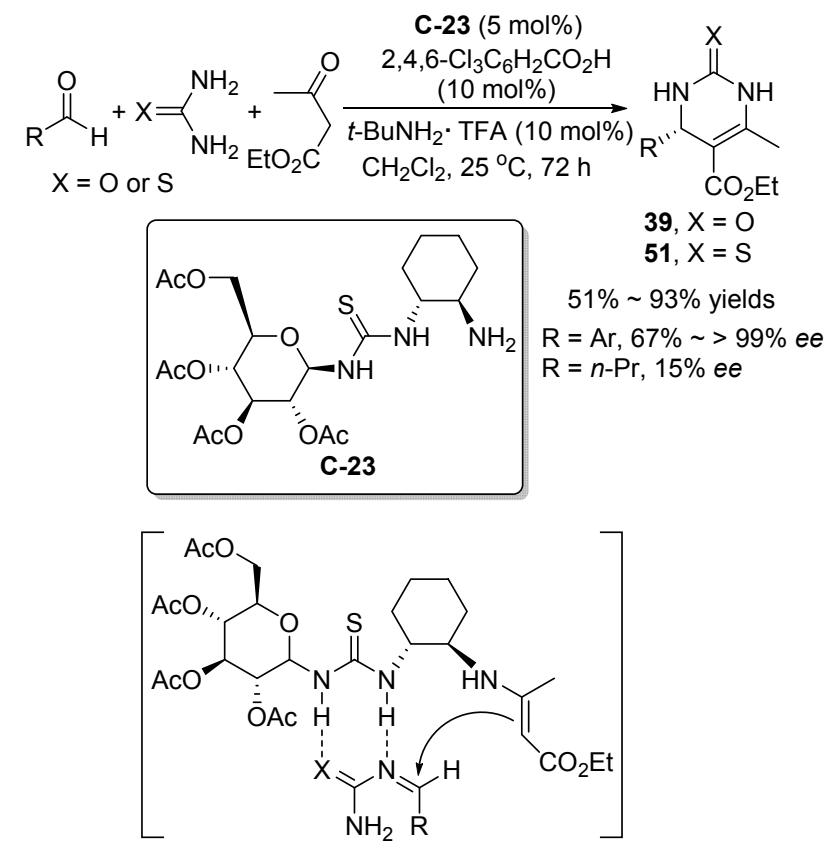

图式 28 伯胺硫脲催化经过 $N$-酰基亚胺中间体的 Biginelli 反 应

Scheme 28 Primary amine-thiourea catalyzed Biginelli reaction involving $N$-acylimine intermediate

2012 年, Maruoka 小组 ${ }^{[60]}$ 报道了用手性顺式环己二
胺衍生的伯胺催化剂 $\mathbf{C}-24$ 催化环状亚胺 52 与酮的不对 称 Mannich 反应，在同样催化剂作用下，仅仅在有或没 有非手性酸作为添加物的情况下，均能高对映选择性的 获得不同绝对构型的产物 53(Scheme 29). 通过研究 Brønsted 酸作为添加物的过程中, 发现酸作为添加物对 烯胺催化过程的立体选择性有很大的影响, 在反应中加 入 $10 \mathrm{~mol} \%$ 的 2,6-二硝基苯甲酸可以有效地逆转相应产 物的对映选择性，同时保持良好的催化活性和立体选择 性. 在同样手性催化剂条件下，能通过简单的改变条件 同时获得两种不同对映体产物的目标，这对手性合成是 非常有用处的. 进一步，该催化体系也能用于酮酯作为 受体的 Aldol 反应. 有趣的是, 水的加入使 Aldol 反应对 映选择性翻转，但是水的加入对 Mannich 反应并没有使 对映选择性翻转.

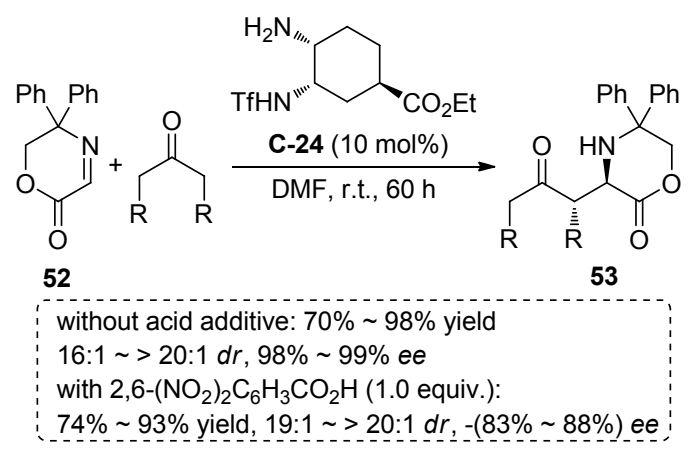

图式 29 非手性酸在不对称 Mannich 反应中诱导的对映选择 性翻转

Scheme 29 Achiral-acid-induced switch in the enantioselectivity of asymmetric Mannich reactions

2017 年, 罗三中和吴骊珠等 ${ }^{[61]}$ 合作报道了可见光 促进的四氢异喹啉 17 和酮的不对称脱氢偶联反应, 如 Scheme 30 所示, 该反应催化体系通过协同多重催化作 用，手性伯胺 C-25 和三氟甲磺酸盐的有机催化剂与酮 作用形成烯胺中间体，而通过 $\mathrm{Ru} / \mathrm{Co}$ 催化作用让四氢异 喹啉 17 原位产生亚胺盐中间体. 该反应催化体系能应 用于广泛的底物范围，对多种不同类型的底物都能以合 理的收率得到目标产物，其中，对不同取代的四氢异喹 啉底物能取得 $3: 1 \sim 12: 1 d r$ 和 95\% 99\% ee 的立体 选择性，对各种环状的酮和两个链状的酮能取得 2 : $1 \sim>19: 1 d r$ 和 $25 \% \sim 97 \% e e$ 的立体选择性, 对简单 的丙酮取得了最差的 $25 \%$ 的对映选择性，对各种不同取 代的 4-取代环己酮的去对称化反应也能取得 4:1 $11: 1 d r$ 和 $87 \% \sim 97 \% e e$ 的立体选择性. 值得注意的是, 尽管得到的产物 54 也为 $\mathrm{C} 1$ 位烷基化的四氢异喹啉结 构，但是和上面提到的在手性伯氨基酸催化得到的产物 18 (Scheme 12)或 34 (Scheme 19) 相对构型相反, 即互为 


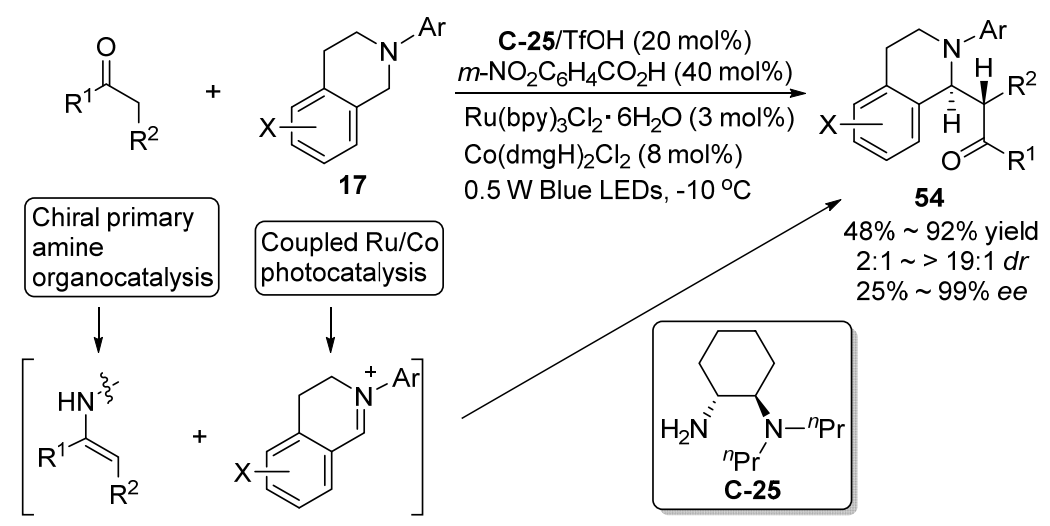

图式 30 可见光促进的四氢异喹啉的不对称交叉脱氢偶联

Scheme 30 Visible-light-promoted asymmetric cross-dehydrogenative coupling of tetrahydroisoquinolines

非对映选择性异构体, 说明手性伯胺催化剂的骨架决定 了最终产物的立体选择性.

同一年, 罗三中小组 ${ }^{[62]}$ 结合电化学氧化和手性伯 胺催化的策略继续实现了四氢异喹啉 17 和酮的氧化偶 联反应(Scheme 31). 该催化体系主要拓展到了各种环 状酮底物，对各种大小的环状酮底物能得到好到高的对 映选择性 $(74 \% \sim 95 \% e e)$, 但是对大环的七元环状环庚 酮取得了差的非对映选择性 $(1.5: 1 \sim 1.3: 1 d r)$. 另外, 作者也报道了一个非环状亚胺作为底物的例子, 对 $\alpha, \beta$ 不饱和酮 4-苯基-3-丁烯-2-酮, 改变伯胺催化剂为苯丙 氨基酸衍生的伯-叔二胺为催化剂, 得到了中等的 59\% $e e$ 值. 进一步用廉价的铅笔芯作为电极, 该电化学氧化 偶联反应也能放大到毫摩尔规模, 对模型反应能获得 $63 \%$ 的收率、 $9: 1 d r$ 和 $93 \% e e$ 的立体选择性. 通过进 一步对照实验, 该反应机理过程认为先通过电化学氧化 得到亚胺盐中间体, 然后与手性伯胺催化剂和酮形成的 烯胺反应产生最后的产品.

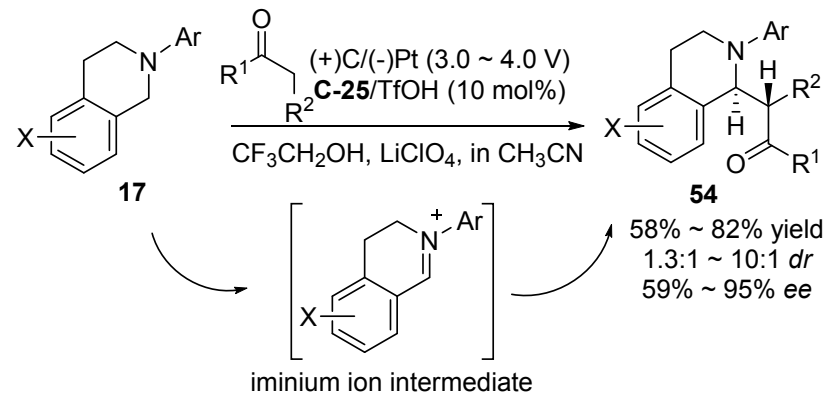

图式 31 电化学氧化和手性伯胺催化合并作用的叔胺氧化偶 联

Scheme 31 Oxidative coupling of tertiary amines by the combination of electrochemical oxidation and chiral primary amine catalysis

最近, Snyder 小组 ${ }^{[63]}$ 报道了含有环内碳氮双键的环
状硝酮 55 作为亚胺底物与甲基酮的不对称 Mannich 型 反应构建 2-取代哌啶衍生物 56, 用手性环己二胺衍生 的双官能的伯胺硫嫝衍生物 C-26 作为催化剂, 能得到 高达 98\%的对映选择性(Scheme 32). 作为底物的环状硝 酮 55 可通过二级胺或羟胺的氧化合成得到, 并且作为 稳定的环状亚胺等价物具有反应活性较强的 $E$ 式碳氮 双键结构. 此外, Mannich 产物中的差胺部分可防止脂 肪族胺 $\alpha$ 位外消旋的可能性，且易被转化为其它含氮化 合物. 在没有催化剂的情况下，环状硝酮和 $\beta$-酮酸之间 的脱羧 Mannich 反应可以在室温下进行，因此不能用手 性催化剂进行不对称诱导. 最后, 以产物中的一个 56a 为起始原料, 经过 8 步全合成, 其中包含一步的 $\beta$-酮酸 的脱羧 Mannich 反应，最后完成了天然产物(一)-lobeline $(57)$ 和 $(-)$-sedinone $(\mathbf{5 8})$ 的全合成. 这一开创性的工作 可能激发更多有趣的通过有机催化向环状硝基化合物 进行亲核加成的方法，而且为制备手性氮杂环提供了一 种潜在的更普适性的方法.
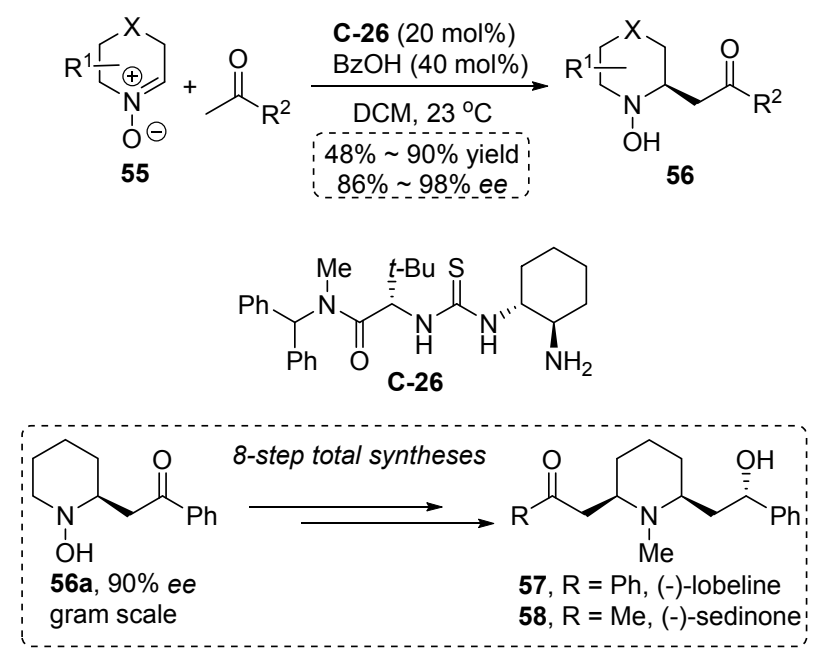

图式 32 伯胺-硫腿催化作用下的环状硝酮的 Mannich 反应 Scheme 32 Primary amine-thiourea catalysis for Mannich-type reactions of cyclic nitrones 


\section{3 结论}

最近十几年, 手性伯胺化合物作为有机小分子催化 剂的不对称加成反应已经取得了很大的发展, 尽管对含 有潜手性的 $\mathrm{C}=\mathrm{N}$ 键的亚胺的不对称加成反应是构建光 学活性的含氮化合物最有效、最直接的方法, 但是应用 手性伯胺催化剂对 $\mathrm{C}=\mathrm{N}$ 键的高对映选择性的加成反应 报道仍然较少. 作为仲胺催化剂的补充, 伯胺催化剂通 常也是通过烯胺和亚胺离子活化, 但是其在催化过程中 含有独特的活泼质子和位阻小的特点, 使其也能在部分 仲胺催化剂表现欠佳的反应中获得优秀的结果. 并且, 用手性伯胺催化剂, 对部分亚胺的不对称加成反应被证 明采用了不同寻常的烯醇式反应机理, 这也拓展了催化 反应的新思路. 基于伯胺催化剂在亚胺的不对称加成反 应中表现的独特优良性能, 进一步研究拓展其它类型的 伯胺催化剂, 用于新的含有 $\mathrm{C}=\mathrm{N}$ 键的亚胺底物的不对 称加成反应将具有重要的学术和应用价值.

\section{References}

[1] Li, Y. M.; Fan, Q. H.; Chen, X. Z. Asymmetric Organic Reactions, Beijing Chemical Industry Press, Beijing, 2005 (in Chinese). (李月明, 范青华, 陈新滋, 不对称有机反应, 北京化学工业出 版社, 北京, 2005.)

[2] Dalko, P. I. Comprehensive Enantioselective Organocatalysis: Catalysts, Reactions, and Applications, Wiley- $\mathrm{VCH}$ Verlag $\mathrm{GmbH} \&$ Co. KGaA, Weinheim, 2013.

[3] Jacobsen, E. N.; MacMillan, D. W. C. Proc. Natl. Acad. Sci. U. S. A. 2010, 107, 20618.

[4] Maruoka, K.; List, B.; Yamamoto, H.; Gong, L.-Z. Chem. Commun. 2012, 48, 10703.

[5] Zhan, G.; Du, W; Chen, Y.-C. Chem. Soc. Rev. 2017, 46, 1675.

[6] Wurz, R. P. Chem. Rev. 2007, 107, 5570.

[7] Palomo, C.; Oiarbide, M.; López, R. Chem. Soc. Rev. 2009, 38, 632.

[8] Erkkilä, A.; Majander, I.; Pihko, P. M. Chem. Rev. 2007, 107, 5416.

[9] Notz, W.; Tanaka, F.; Barbas, C. F., III Acc. Chem. Res. 2004, 37, 580 .

[10] Mukherjee, S.; Yang, J. W.; Hoffmann, S.; List, B. Chem. Rev. 2007, 107, 5471.

[11] List, B.; Lerner, R. A.; Barbas, C. F., III. J. Am. Chem. Soc. 2000, 122, 2395.

[12] Donslund, B. S.; Johansen, T. K.; Poulsen, P. H.; Halskov, K. S.; Jørgensen, K. A. Angew. Chem., Int. Ed. 2015, 54, 13860.

[13] Kano, T.; Maruoka, K. Chem. Sci. 2013, 4, 907

[14] Xu, L.-W.; Luo, J.; Lu, Y. Chem. Commun. 2009, 1807.

[15] Jiang, L.; Chen, Y.-C. Catal. Sci. Technol. 2011, 1, 354.

[16] Melchiorre, P. Angew. Chem., Int. Ed. 2012, 51, 9748.

[17] Zhang, L.; Luo, S. Synlett 2012, 1575.

[18] Zhang, L.; Fu, N.; Luo, S. Acc. Chem. Res. 2015, 48, 986.

[19] Reddy, U. V. S.; Chennapuram, M.; Seki, C.; Kwon, E.; Okuyama, Y.; Nakano, H. Eur. J. Org. Chem. 2016, 4124.

[20] Luo, S.; Xu, H.; Li, J.; Zhang, L.; Cheng, J.-P. J. Am. Chem. Soc. 2007, 129, 3074.
[21] Xie, J.-W.; Chen, W.; Li, R.; Zeng, M.; Du, W.; Yue, L.; Chen, Y.-C.; Wu, Y.; Zhu, J.; Deng, J.-G. Angew. Chem., Int. Ed. 2007, 46, 389.

[22] Gefflaut, T.; Blonksi, C.; Perie, J.; Willson, M. Prog. Biophys. Molec. Biol. 1995, 63, 301.

[23] Enders, D.; Reinhold, U. Tetrahedron: Asymmetry 1997, 1895.

[24] Kobayashi, S.; Mori, Y.; Fossey, J. S.; Salter, M. M. Chem. Rev. 2011, 111, 2626.

[25] Wang, D.; Hou, C.; Chen, L.; Liu, X.; An, Q.; Hu, X. Chin. J. Org. Chem. 2013, 33, 1355 (in Chinese).

(王东, 侯传金, 陈丽风, 刘小宁, 安庆大, 胡向平, 有机化学, 2013, 33, 1355.)

[26] Xie, J.-H.; Zhu, S.-F.; Zhou, Q.-L. Chem. Rev. 2011, 111, 1713.

[27] Qin, Y.; Lv, J.; Luo, S. Tetrahedron Lett. 2014, 55, 2423;

[28] Cheng, M.-X.; Yang, S.-D. Synlett 2017, 28, 159.

[29] Ibrahem, I.; Zou, W.; Engqvist, M.; Xu Y.; Córdova, A. Chem.-Eur. J. 2005, 11, 7024 .

[30] Ramasastry, S. S. V.; Zhang, H.; Tanaka, F.; Barbas III, C. F. J. Am Chem. Soc. 2007, 129, 288.

[31] Cheng, L.; Wu, X.; Lu, Y. Org. Biomol. Chem. 2007, 5, 1018.

[32] Cheng, L.; Han, X.; Huang, H.; Wong, M. W.; Lu, Y. Chem. Commun. 2007, 4143.

[33] Dziedzic, P.; Córdova, A. Tetrahedron: Asymmetry 2007, 18, 1033.

[34] Zhang, H.; Ramasastry, S. S. V.; Tanaka, F.; Barbas III, C. F. $A d v$. Synth. Catal. 2008, 350, 791.

[35] Westermann, B.; Neuhaus, C. Angew. Chem., Int. Ed. 2005, 44, 4077.

[36] Zhang, G.; Ma, Y.; Wang, S.; Kong, W.; Wang, R. Chem. Sci. 2013, 4, 2645.

[37] Mondal, B.; Pan, S. C. Org. Biomol. Chem. 2014, 12, 9789.

[38] Zhang, S.; Li, L.; Hu, Y.; Zha, Z.; Wang, Z.; Loh, T.-P. Org. Lett, 2015, 17, 1050.

[39] Zhang, S.; Li, L.; Hu, Y.; Li, Y.; Yang, Y.; Zha, Z.; Wang, Z. Org. Lett. 2015, 17, 5036.

[40] Otsuki, T.; Kumagai, J.; Kohari, Y.; Okuyama, Y.; Kwon, E.; Seki, C.; Uwai, K.; Mawatari, Y.; Kobayashi, N.; Iwasa, T.; Tokiwa, M.; Takeshita, M.; Maeda, A.; Hashimoto, A.; Turuga, K.; Nakano, H. Eur. J. Org. Chem. 2015, 7292.

[41] Dai, J.; Xiong, D.; Yuan, T.; Liu, J.; Chen, T.; Shao, Z. Angew. Chem., Int. Ed. 2017, 56, 12697.

[42] Chen, S.; Houk, K. N. J. Org. Chem. 2018, 83, 3171.

[43] You, Y.; Zhang, L.; Cui, L.; Mi, X.; Luo, S. Angew. Chem., Int. Ed. 2017, 56, 13814

[44] You, Y.; Luo, S. Org. Lett. 2018, 20, 7137.

[45] Hou, H.; Zhu, S.; Atodiresei, I.; Rueping, M. Eur. J. Org. Chem. 2018, 1277.

[46] Yang, Q.; Zhang, J.; Jia, Z.; Yang, C.; Zhang, L.; Luo, S. Asian J. Org. Chem. 2019, 8, 1049.

[47] Duan, J.; Li, P. Catal. Sci. Technol. 2014, 4, 311.

[48] Chen, W.; Du, W.; Duan, Y.-Z.; Wu, Y.; Yang, S.-Y.; Chen, Y.-C. Angew. Chem., Int. Ed. 2007, 46, 7667.

[49] Ding, D.; Zhao, C.-G. Eur. J. Org. Chem. 2010, 3802.

[50] Cai, Y.-F.; Yang, H.-M.; Li, L.; Jiang, K.-Z.; Lai, G.-Q.; Jiang, J.-X.; Xu, L.-W. Eur. J. Org. Chem. 2010, 4986.

[51] Zhou, W.; Zhao, J.-G.; Lin, J.; Xu, Y.-X.; Liu, J.; Zhao, S.-J.; Xie, T. J. Hangzhou Normal Univ. (Nat. Sci. Ed.) 2012, 11, 352 (in Chinese). 
(周伟, 赵金刚, 林晶, 徐燕霞, 刘琚, 赵淑娟, 谢恬, 杭州师范 大学学报 (自然科学版), 2012, 11, 352.)

[52] Liu, Y.; Kang, T.-R.; Liu, Q.-Z.; Chen, L.-M.; Wang, Y.-C.; Liu, J.; Xie, Y.-M.; Yang, J.-L.; He, L. Org. Lett. 2013, 15, 6090.

[53] Kang, Y. K.; Kim, D. Y. Adv. Synth. Catal. 2013, 355, 3131.

[54] Wang, Y.-Q.; Cui, X.-Y.; Ren, Y.-Y.; Zhang, Y. Org. Biomol. Chem. 2014, 12, 9101 .

[55] Cui, X.-Y.; Duan, H.-X.; Zhang, Y.; Wang, Y.-Q. Chem. Asian J. 2016, 11, 3118.

[56] Yalalov, D. A.; Tsogoeva, S. B.; Shubina, T. E.; Martynova, I. M.; Clark, T. Angew. Chem., Int. Ed. 2008, 47, 6624.

[57] Wang, Y.; Yang, H.; Yu, J.; Miao, Z.; Chen, R. Adv. Synth. Catal. 2009, 351, 3057.
[58] Wang, Y.; Yu, J.; Miao, Z.; Chen, R. Org. Biomol. Chem. 2011, 9, 3050.

[59] Yang, Q.-C.; Peng, L.; Wang, F.-Y.; Xu, X.-Y.; Wang, L.-X. Chin. J. Synth. Chem. 2013, 21, 237 (in Chinese).

(杨清川, 彭林, 王斐英，徐小英，王立新，合成化学，2013，21， 237.)

[60] Moteki, S. A.; Han, J.; Arimitsu, S.; Akakura, M.; Nakayama, K.; Maruoka, K. Angew. Chem., Int. Ed. 2012, 51, 1187.

[61] Yang, Q.; Zhang, L.; Ye, C.; Luo, S.; Wu, L.-Z.; Tung, C.-H. Angew. Chem., Int. Ed. 2017, 56, 3694.

[62] Fu, N.; Li, L.; Yang, Q.; Luo, S. Org. Lett. 2017, 19, 2122.

[63] Lisnyak, V. G.; Lynch-Colameta, T.; Snyder, S. A. Angew. Chem., Int. Ed. 2018, 57, 15162. 